\title{
L'impact du Brexit sur l'Afrique en période de crise Corona le cas de l'Afrique du Sud, du Nigeria, du Ghana et du Kenya
}

\section{Dirk Kohnert ${ }^{1}$}

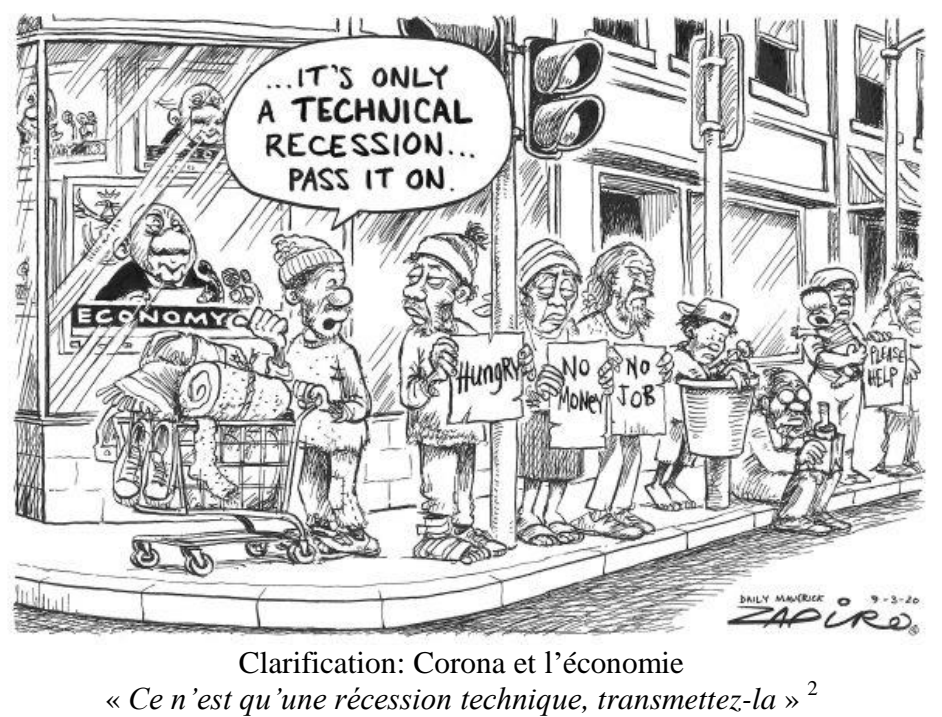

Résumé : Bien que la Grande-Bretagne ait jusqu'à présent été la plus durement touchée par la pandémie Corona parmi les États membres de l'UE, Johnson persiste à quitter l'UE fin 2020, quel qu'en soit le coût. Vraisemblablement, la pandémie aura un impact beaucoup plus important sur le commerce africain du Royaume-Uni qu'un Brexit sans accord. En Afrique subsaharienne, l'Afrique du Sud a probablement été le pays le plus durement touché par le Brexit et Corona. Cependant, les pauvres, travaillant principalement dans le secteur informel, étaient plus préoccupés par l'impact économique de la pandémie que par la maladie elle-même. Au Nigeria, beaucoup de gens considéraient Corona comme un fléau pour les riches et l'élite. Le président Buhari a partagé l'orgueil de nombreux Britanniques selon lesquels ils sont moins vulnérables à la pandémie et pourraient continuer avec des plans de haut vol après le Brexit. Le Ghana compte parmi les pays d'Afrique subsaharienne qui ont été les plus durement touchés par la pandémie de Corona. Mais contrairement à l'Afrique du Sud et au Nigeria, les effets directs de la pandémie sur le ralentissement de son économie ne sont pas aussi importants que dans d'autres États africains. Au Kenya, le nombre de décès par effet Corona a été beaucoup plus faible que pour la pandémie de SRAS de 2003, mais la transmission du virus COVID-19 a été nettement plus importante. Néanmoins, de nombreux Kenyans ont vu le Brexit comme une bénédiction déguisée, car ils portaient leur espoir sur le IDE massif des investisseurs britanniques. En tout état de cause, il est clair, sans aucun doute, que ceux qui souffriront le plus des effets combinés de la pandémie Corona et du Brexit en Afrique (et vraisemblablement dans le monde entier) sont les pauvres et les vulnérables.

Mots clés: Corona, Brexit, Afrique, Royaume-Uni, UE, commerce international, récession économique, pauvreté, Afrique du Sud, Nigeria, Ghana, Kenya

JEL-Code: F13, F35, F54, F63, G15, I1, N17, N47, N67, O17, P16, Z13

\footnotetext{
${ }^{1}$ Dirk Kohnert, expert associé, GIGA-Hambourg, Allemagne. Version française révisée: 14 mai 2021.

${ }^{2}$ Caricature sur la déclaration de Cyril Ramaphosa selon laquelle la récession économique de l'Afrique du Sud à partir de 2019 n'était qu'une récession technique. @CyrilRamaphosa, Zapiro, @ zapiro, Zapiro's cartoon @ dailymaverick, (18 March 2020) https://zapiro.com/200309dm
} 


\section{Introduction}

La sortie du Royaume-Uni de l'Union européenne (l’UE) a eu lieu le 31 janvier 2020, tel qu'administré par l'accord de retrait signé le 24 janvier 2020. L'accord prévoyait une période de transition jusqu'au 31 décembre 2020, pour renégocier la relation à long terme entre le Royaume-Uni et l'Union européenne. Londres se conforme initialement à toutes les règles de l'UE et continue de verser des contributions, n'a plus son mot à dire dans les organes de l'UE. La période de transition pourrait être prolongée au-delà du 31 décembre 2020 au plus tard le 30 juin 2020. Cependant, un Brexit sans accord est actuellement plus probable. L'impact grave du Brexit sur le Royaume-Uni sera aggravé par la crise Corona. Bien qu'une deuxième vague Corona se profile sur le Royaume-Uni qui menace d'aggraver encore plus l'impact économique de la pandémie sur l'île, le gouvernement du Premier ministre britannique Boris

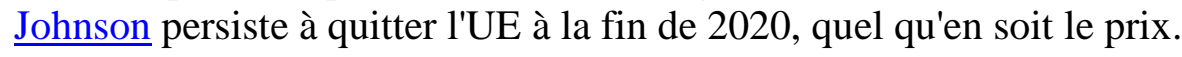

Selon les dernières prévisions de l'Office for National Statistics (ONS, Londres), le produit intérieur brut (PIB) mensuel a baissé de 20,4\% en avril 2020, la plus forte baisse que le Royaume-Uni ait jamais connue, plus de trois fois plus importante qu'en mars et presque dix fois plus grande que la chute la plus raide pré-COVID-19. Pratiquement tous les secteurs de l'économie ont été touchés, les pubs, l'éducation, la santé et les ventes de voitures ayant contribué le plus à cette chute historique. De plus, le commerce de la Grande-Bretagne avec le reste du monde a également été gravement affecté par la pandémie, avec une forte baisse des importations et des exportations de voitures, de carburants, d'œuvres d'art et de vêtements (ONS, 2020). Les effets économiques négatifs (potentiels) du Brexit sur le Royaume-Uni (Brown et al, 2019; Kohnert, 2018) aggraveraient encore la récession économique imminente. Selon Andy Haldane, l'économiste en chef de la Banque d'Angleterre, le sous-emploi et le chômage en sont le résultat. Plus de 8 millions d'indépendants et autres personnes mis en congé étaient concernés, soit près d'un tiers de l'ensemble des salariés du secteur privé, un niveau jamais vu auparavant sur le marché du travail. Plus de 1,5 millions d'autres pourraient avoir perdu leur emploi, à en juger par les nouvelles créances privées universelles. Environ $20 \%$ des ménages ont peur de faire face à des difficultés financières importantes en raison de la pandémie. Et il est presque certain que les plus durement touchés seront les pauvres, les moins bien payés, y compris les jeunes et les femmes (Haldane, 2020). Ainsi, 68\% des adultes britanniques s'inquiétaient de l'effet du Coronavirus (COVID-19) sur leur vie début juin (ONS, 2020). Cela d'autant plus que la gestion de la pandémie par le gouvernement a entrainé entre temps le nombre de morts de Covid-19 le plus élevé d'Europe (Campbell et al, 2020).

Dans ces conditions, on peut s'attendre à ce que Londres soit plus que jamais désireuse de bénéficier d'un éventuel renflouement commun de l'UE pour les années à venir, tant pour les conséquences économiques que sanitaires de la pandémie. Ceci est d'autant plus vrai, en raison des effets négatifs supplémentaires du Brexit sur l'emploi. Cependant, Johnson ne semble pas se préoccuper. Et on peut se demander si ceux qui ont voté le Premier ministre au pouvoir agiraient maintenant autrement. En fait, certains politiciens se sont déjà aventurés à deviner, le gouvernement britannique pourrait provoquer une sortie chaotique sans accord de l'UE pour détourner l'attention de son échec dans la crise du COVID 19 (Mason, 2020).

Quoi qu'il en soit, apparemment, il y a un lien entre l'argument de fond du Brexit et la gestion de la crise Corona. Le 31 janvier 2020, l'adhésion du Royaume-Uni à l'Union européenne a pris fin 47 ans après son adhésion. Les arguments du Brexiteer ainsi que le raisonnement des Corona-idéologues se sont centrés sur des fantasmes sur la suprématie britannique en matière de commerce international (Brexit) et son génie créatif scientifique et inventif pour faire face 
à la pandémie. Les deux perceptions avec beaucoup d'allusions à le rôle de l'Angleterre dans le Seconde Guerre mondiale. Cependant, l'analogie de la guerre est profondément trompeuse, car le Brexit implique l'éclatement du marché réglementaire et douanier et ouvrirait le marché britannique non seulement aux producteurs européens, mais à ceux du monde entier. Le tableau mythique de l'innovation britannique s'applique également aux arguments du Brexiteer qui reposent sur le leadership supposé du Royaume-Uni en matière de créativité et d'innovation (Edgerton, 2020) et à l'idée que les Britanniques n'avaient pas besoin des Européens, ou du moins qu ' «ils ont besoin de nous plus que nous n'en avons besoin » (English, 2020). Au contraire, un Brexit sans accord pourrait anéantir les chances du Royaume-Uni de diriger la recherche mondiale sur Covid-19. Des lauréates du prix Nobel, comme Sir Andre Geim de l'Université de Manchester, ont averti que la Grande-Bretagne perdrait le statut de «superpuissance » si l'accès au programme de financement de la recherche de l'UE de 100 milliards d'euros (85 milliards de livres sterling), Horizon Europe, serait interdit, qui durera de 2021 à 2027. Depuis le début du programme actuel de l'UE, Horizon 2020 (auquel succédera Horizon Europe), le Royaume-Uni a reçu plus de 1,5 milliards de livres sterling de revenus ERC et 776 millions de livres sterling de subventions MSCA (actions Marie Skłodowska Curie) - plus que tout autre pays de l'UE, et un cinquième du total (Helm \& McKie, 2020).

En outre, une constellation économique et politique aussi précaire ne concerne pas seulement la Grande-Bretagne. Il y a une tendance générale selon laquelle les électeurs des régions où les industries sont exposées à une concurrence croissante des importations sont susceptibles de tomber dans les déchaînements politiques. Les enjôleur politiques bénéficient d'un soutien populaire croissant aux partis prêchant le nationalisme, l'isolationnisme et un retrait des engagements internationaux contraignants. Il faut souligner que les facteurs tant économiques que culturels jouent un rôle déterminant à cet égard (Colantone \& Staning 2018). Les régions concernées ne sont pas seulement touchées par la baisse des salaires, mais aussi par une montée de l'autoritarisme et de l'hostilité vis-à-vis des «étrangers ». En bref, il existe un rapport résilient entre les difficultés économiques régionales dans les démocraties et les gains politiques des partis radicaux de droite.

En revanche, les entreprises britanniques avaient apparemment une vision plus réaliste et semblaient bien conscientes du risque imminent. Ils votaient déjà avant la crise de Corona avec leur argent, des méchantes langues maintiendraient, comme des rats désertant un navire en train de couler. De plus, l'incertitude liée au Brexit a conduit à une perte de valeur de marché des entreprises internationales les plus exposées au Brexit ainsi qu'à une réduction des recrutements et des investissements, car les entreprises internationales s'attendaient massivement à des effets directs négatifs du Brexit. En particulier, les entreprises s'attendaient à des difficultés dues à des divergences réglementaires, à une mobilité réduite de la maind'œuvre et à un accès limité au commerce (Hassan et al 2021).

D'un autre côté, le nombre de projets d'investissement de l'UE27 au Royaume-Uni n'a diminué que d'environ $9 \%$, ce qui suggère que le Royaume-Uni serait plus exposé aux coûts de la désintégration économique que les autres États membres de l'UE (Breinlich et al 2020). Soit dit en passant, aucun syndicat n'a osé qualifier ce comportement d '«antipatriotique». Apparemment, la mobilité internationale des capitaux est toujours accueillie comme un signe d'adaptation innovante dans les moments difficiles. Alors que la mobilité de la main-d'œuvre équivaut souvent à une concurrence déloyale, comme dans le cas des travailleurs d'Europe de l'Est qui ont tenté leur chance au Royaume-Uni, ce qui a après tout déclenché le vote du Brexit. 
Pour revenir à la question du Brexit, il reste à se demander si les vœux pieux de la GrandeBretagne concernant le remplacement du marché intérieur de l'UE par des liens étendus avec ses anciens marchés du Commonwealth, d'abord et avant tout avec le marché américain, se réaliseront. Le gouvernement à Londres il-même était plutôt prudente. Il a estimé début mars que l'amélioration du commerce bilatéral avec les États-Unis pourrait se traduire par une prospérité plutôt modeste, son propre produit intérieur brut augmentant entre $0,07 \%$ et $0,16 \%$, mais seulement après environ 15 ans. Pourtant, les États-Unis ne sont que le deuxième partenaire commercial britannique après l'UE. De plus, le gouvernement britannique s'était jusqu'à présent opposé aux vœux américains, comme une ouverture complète de l'agriculture pour les investisseurs américains et l'accès au National Health Service (NHS) pour les fabricants pharmaceutiques américains (Triebe, 2020). La question de savoir si les ambitions de Londres concernant l'ouverture des marchés africains seront plus prometteuses est encore plus douteuse, car le reste de l'UE-27 ne reste pas chômer.

Quant à l'UE, la Commission européenne et le Service européen pour l'action extérieure ont présenté début mars 2020 un projet de stratégie globale de coopération avec l'Afrique en vue du sixième sommet UE-Afrique en octobre 2020. Mais la crise Corona et ses effets, pas seulement sur le L'UE et l'Afrique, mais dans le monde entier ont réduit ces plans de haut vol à la pagaille ${ }^{3}$.

Bien que l'Europe soit gravement touchée par la pandémie, l'Afrique risque d'en souffrir encore plus. Cependant, il peut suivre une voie différente de celle d'autres régions du monde selon l'Organisation mondiale de la santé (OMS). Six mois après la détection du premier cas africain, la hausse des cas a été plus graduelle que les flambées rapides ailleurs dans le monde (Giles \& Mwai, 2020). Au 6 août 2020, le continent avait concédé un total d'un million de cas prouvés. L'Afrique du Sud représentait plus de la moitié de tous les cas signalés, le quatrième plus grand nombre de cas au monde (Giles \& Mwai, 2020). Parmi les autres pays fortement infectés figurent l'Égypte, le Nigeria, le Ghana et l'Algérie. À propos, même au Royaume-Uni, les migrants Africains sont plus de quatre fois plus susceptibles de mourir de Covid-19 que les habitants indigènes, principalement en raison des différences sociales et économiques, la santé, l'éducation et les conditions de vie des communautés (Booth \& Barr, 2020). Après avoir tenu compte de l'âge, d'autres caractéristiques socio-démographiques et des mesures de l'état de santé et de l'incapacité auto déclarés lors du recensement de 2011, le risque de décès lié au COVID-19 chez les hommes et les femmes d'origine ethnique noire a été réduit à 1,9 fois plus probable que ceux d'origine ethnique blanche, selon le British Office for National Statistics (date de sortie: 7 mai 2020).

Selon la Banque mondiale, la pandémie coûtera à la région entre 37 et 79 milliards de dollars. Le déclin du commerce mondial dû à la crise Corona affectera l'Afrique à travers l'effondrement du commerce international et des chaînes d'approvisionnement mondiales, la baisse des envois de fonds, les flux de capitaux et les problèmes de respect des obligations de paiement en devises étrangères (Brugner \& Schuch, 2020: 6).

\footnotetext{
${ }^{3}$ Cependant, le Partenariat européen-africain pour les essais cliniques (EDCTP), établi en 2003 pour soutenir le développement de médicaments nouveaux ou améliorés et pour développer les capacités en Afrique, peut être une exception. Il a investi plus de $600 \mathrm{M} €$ depuis 2003 et a souvent été perçu comme un projet phare. Il avait l'intention de financer des projets avec un budget allant jusqu'à 28 millions d'euros à partir d'Horizon 2020, ainsi que des financements supplémentaires de ses États membres pour améliorer la préparation à la pandémie de Coronavirus en Afrique subsaharienne. Cet investissement d'Horizon 2020 est conforme à l'engagement de l'UE à intensifier la coopération scientifique avec l'Union africaine, tel qu'énoncé dans la stratégie globale de la Commission pour l'Afrique adoptée le 9 mars 2020 (Brugner \& Schuch, 2020: 3).
} 


\section{Carte 1: Pays membres africains du Commonwealth ${ }^{4}$}

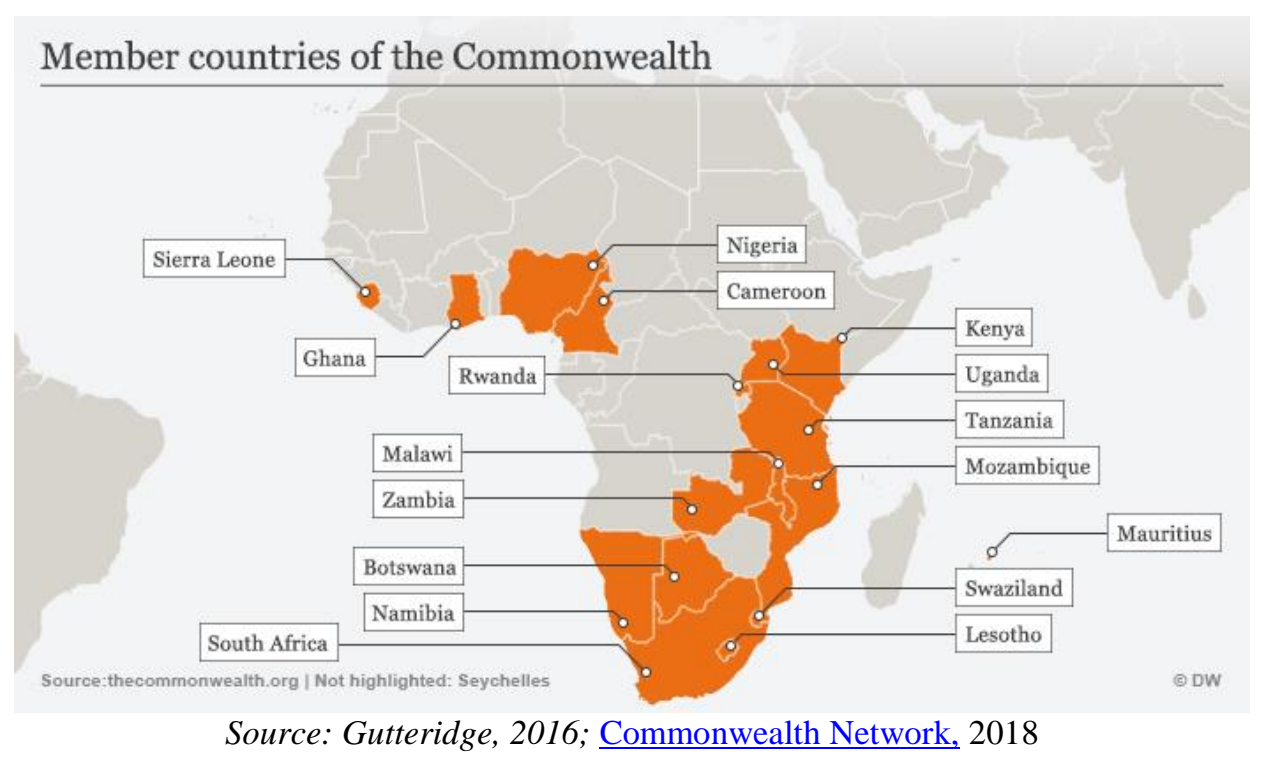

Les plus grandes économies de la région, parmi lesquelles les poids lourds du Commonwealth africain, l'Afrique du Sud et Nigeria, devraient être les plus durement touchés par ces effets économiques. L'effondrement des prix du pétrole et des matières premières, par exemple, aura un impact dévastateur sur plusieurs économies africaines qui en dépendent pour plus de la moitié de leurs exportations (Laporte, 2020). Pour émasculer la menace de récession économique, les ministres africains des Finances ont appelé à une relance économique d'au moins 100 milliards de dollars américains pour réduire les effets du Coronavirus. Mais ce ne sera qu'une goutte d'eau dans la mer. Des analyses scientifiques ont montré que le stimulus moyen en Europe jusqu'à présent est 15 fois plus élevé que dans les pays africains plus pauvres (Laporte, 2020). De plus, les envois de fonds (rémitance) se sont taris à cause de la crise Corona avec des conséquences fatales pour les pauvres et les vulnérables (Pelz, 2020). Les reversements avaient considérablement augmenté ces dernières années et constituaient près de trois fois le montant de l'aide publique au développement, c'est-à-dire que 48 milliards de dollars (42 milliards d'euros) avaient été envoyés en Afrique subsaharienne en 2019. En 2020, ce chiffre devrait diminuer à environ 37 milliards de dollars (34 milliards d'euros) à cause de Corona, car la plupart des migrants africains en Europe sont des travailleurs peu qualifiés, travaillant dans le secteur informel, par exemple, dans les magasins de détail, les hôtels, le tourisme ou comme ouvriers agricoles quotidiens. Beaucoup de ces emplois ont dû cesser leurs activités en raison du verrouillage ou des mesures de distanciation sociale. Les envois de fonds devraient chuter dans toutes les régions du Groupe de la Banque mondiale, mais plus particulièrement en Europe et en Asie centrale (27,5\%), suivies de l'Afrique subsaharienne $(23,1 \%)$ (Banque mondiale, 2020).

On s'inquiète également de plus en plus d'une éventuelle perturbation des chaînes d'approvisionnement alimentaire en raison de l'impact du virus sur les fermes et les importations alimentaires. Les personnes occupant des emplois informels et vivant au jour le jour sont particulièrement concernées. Selon les estimations de l'Union africaine, près de 20 millions d'emplois sont menacés sur l'ensemble du continent. Beaucoup d'entre eux disent qu'ils préféreraient mourir de Corona plutôt que de faim (Kennedy, 2020; Bavier et

\footnotetext{
${ }^{4}$ La Gambie (Afrique de l'Ouest, réintégrée en 2018) et les Seychelles, ne sont pas mises en évidence sur la carte; Le Zimbabwe se retire en 2003.
} 
Paravicini, 2020, Schwettmann, 2020). Dans tous les cas, il est parfaitement clair que ceux qui souffriront le plus des effets combinés de la pandémie Corona et du Brexit sont les pauvres et les nécessiteux.

Graphique 1: Envois de fonds vers l'Afrique subsaharienne en 2018 , par pays (en milliards de dollars américains)

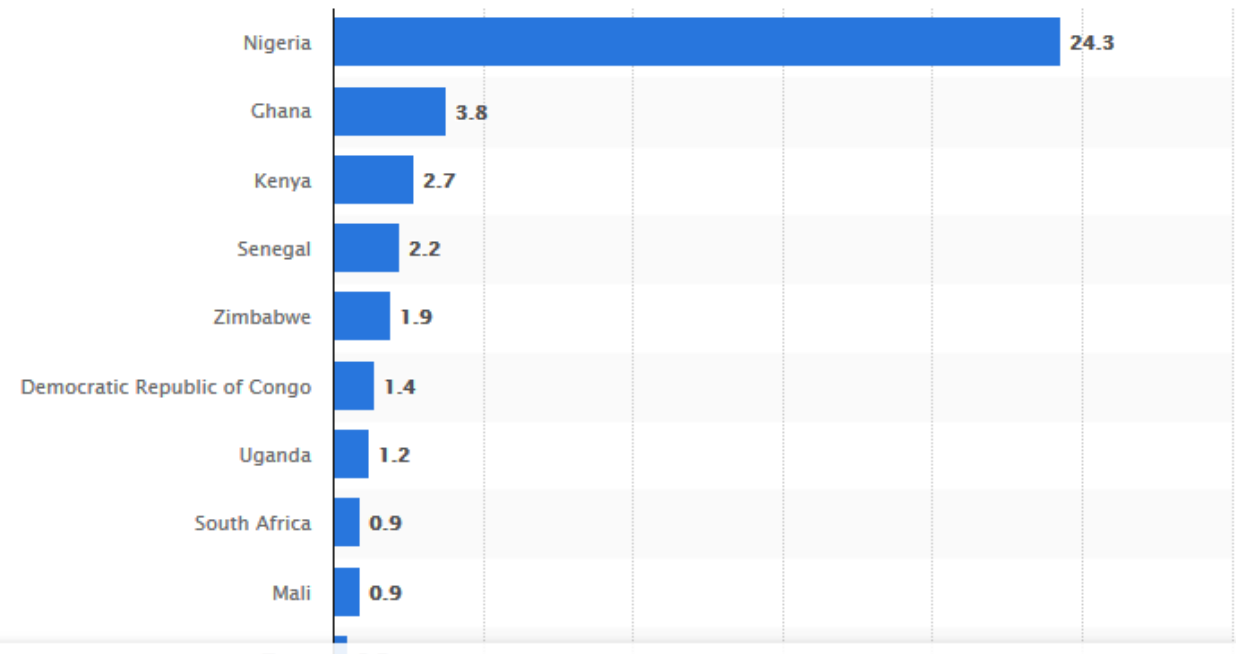

Source: Statistica, June 25, 2020

\section{Carte 2: Vue globale de l'état actuel des affaires Corona en Afrique}

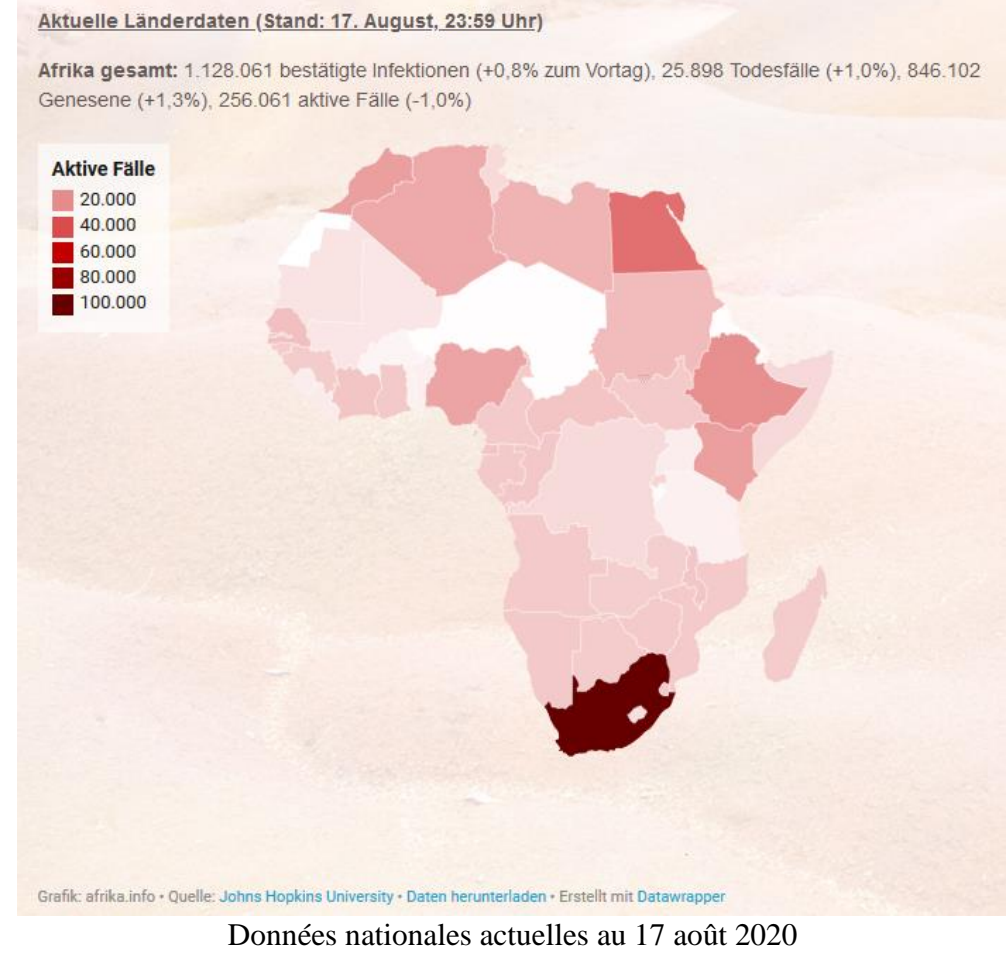

Total Afrique: 1.128.061 infections confirmées (+ 0.8\% la veille), 25.898 décès $(+1.0 \%), 846.102$ personnes récupérées $(+$ $1.3 \%), 256.061$ cas actifs (-1.0\%). Source: Daten \& Fakten: Das Coronavirus in Afrika, Salzburg: afrika-info

En bref, il est déjà douteux que le Royaume-Uni puisse se sortir de la crise Corona après le Brexit sans la coopération éprouvée avec l'UE. Il est encore plus improbable que la GrandeBretagne, à elle seule, ait le pouvoir supplémentaire d'aider ses anciennes colonies africaines à 
faire face non seulement aux conséquences de la pandémie Corona, mais aussi à l'impact d'un Brexit sans accord.

Dans les sections suivantes, une analyse plus détaillée des effets combinés (potentiels) de la propagation du Covid-19 et du Brexit sur les États membres du Commonwealth britannique en Afrique fera l'objet d'une plus grande attention en prenant l'exemple de l'Afrique du Sud, du Nigeria, du Ghana et du Kenya, avec un accent particulier sur impact sur les couches sociales les plus défavorisées de la société.

\section{Graphique 2: Comparaison de l'épidémie de Covid-19 en Afrique nombre de cas par jour, moyenne mobile sur sept jours. Chaque région à sa propre échelle.}

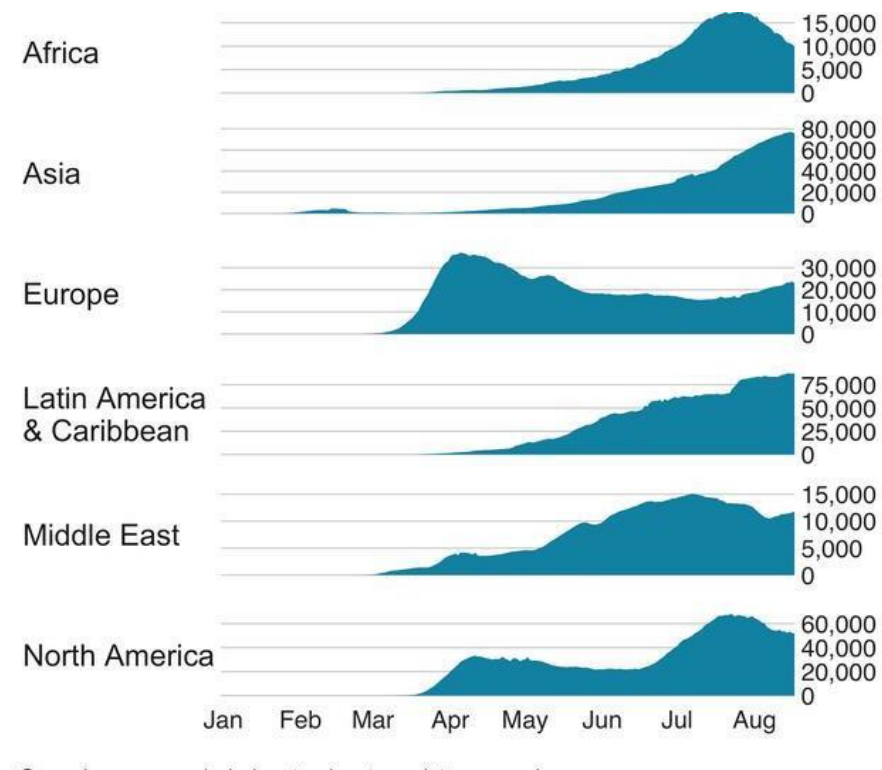

Oceania cases excluded as too low to register on scale

Source: ECDC and national public health agencies, data up to 16 August BBC

Source: Giles \& Mwai, 2020

\section{(1) South Africa, Brexit et Corona}

\section{L'impact de Corona sur l'Afrique du Sud}

Selon les données disponibles, l'Afrique du Sud a été l'un des pays africains les plus durement touches.

Au 15 juin 2020, le nombre cumulé de cas confirmés de COVID-19 en Afrique du Sud était de 73 533, dont la majeure partie provenait de la province du Western Cape Province (60\%), suivie de Gauteng (17\%) et du Eastern Cape (14\%). Le nombre total de décès signalés était de 1,568 (NDP-2020). Pour éviter «une énorme catastrophe», le président Cyril Ramaphosa avait ordonné le 23 mars un verrouillage national de trois semaines, y compris la fermeture des frontières, la libération d'environ 19000 prisonniers (12\% d'un total de 155000 détenus dans les prisons du pays) et une interdiction de vendre de l'alcool, soutenue par l'armée sudafricaine, du 26 mars au 16 avril 2020 (Thielke, 2020). 


\section{Graphique 3 : L'augmentation rapide .}

Afrique, cas confirmés de Covid-19, pays sélectionnés, jusqu'au 25 mars 2020

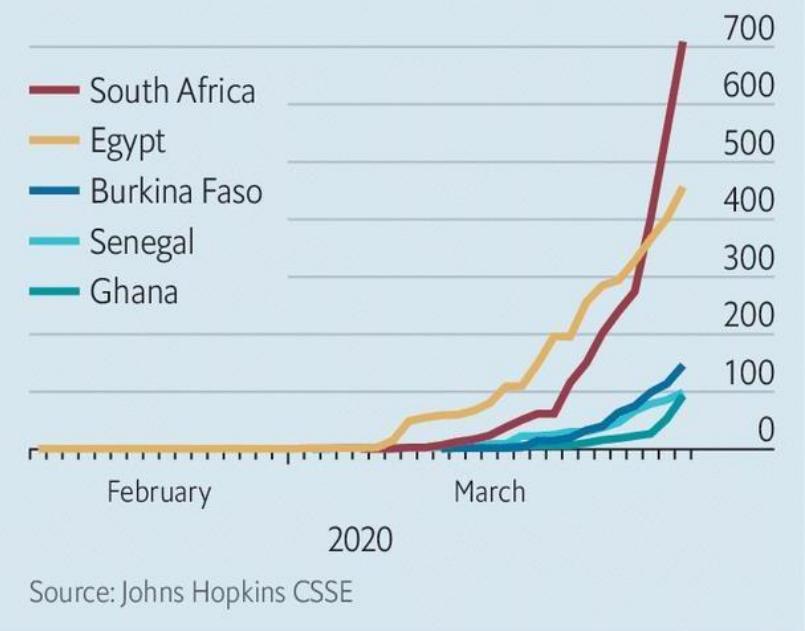

The Economist

Source: The Economist, London

\section{Graphique 4: trajectoire de Covid-19 en Afrique du Sud par rapport au reste}

COVID-19 trajectory in South Africa compared to the rest

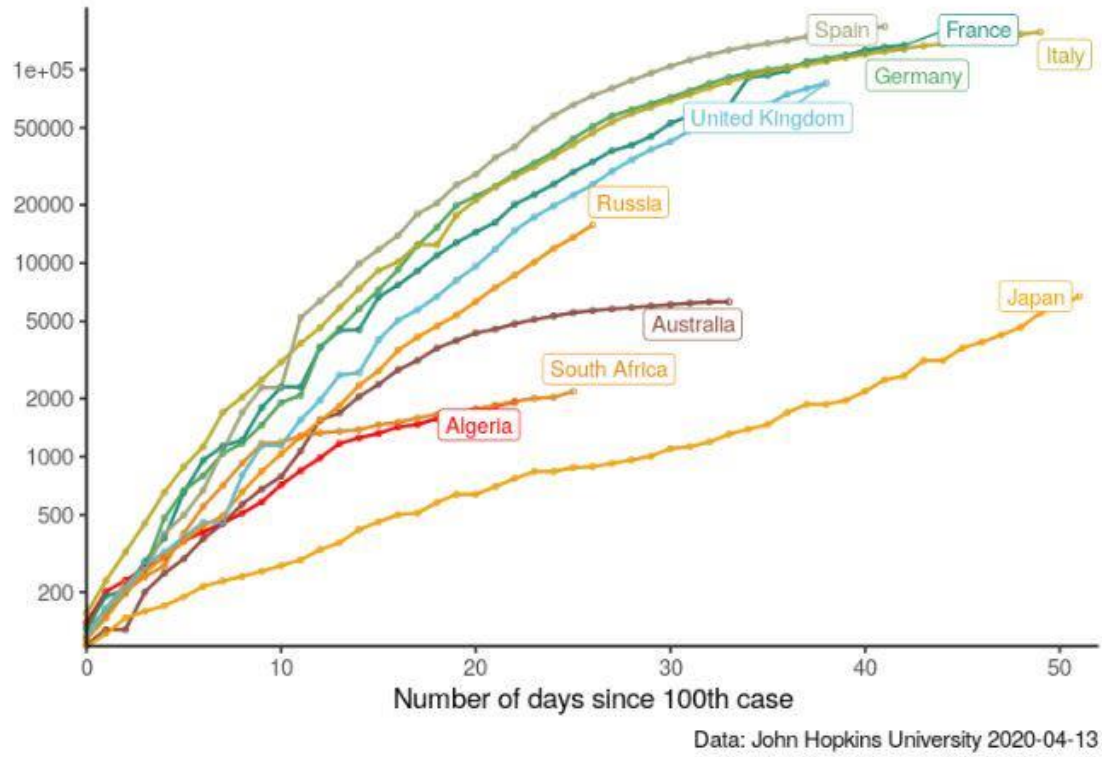

Source: South Africa's response to Covid-19 is 'world-class' and here's why. 947.co.za.

Selon le directeur de Focal Africa ${ }^{5}$, Marcus Hollington, l'Afrique du Sud comptait parmi les cinq premiers pays de classe mondiale luttant contre le Corona-virus, en raison d'un verrouillage rapide ainsi que de mesures de distanciation sociale très strictes pour essayer de lutter contre le virus, ce qui a contribué à « l'aplatissement du (infection)» (Hollington, 2020). Les personnes défavorisées vivant dans le secteur informel, notamment dans les townships, où il est pratiquement impossible d'appliquer des mesures de distanciation sociale et d'hygiène, ont été les plus gravement touchées par la pandémie (Schwettmann, 2020: 11).

\footnotetext{
${ }^{5} \underline{\text { Research }}$ (FAR), Services d'information, Germiston, Gauteng, Afrique du Sud, fondée en 2020.
} 
Cependant, la plupart des Sud-Africains, notamment les pauvres, travaillant principalement dans le secteur informel, étaient plus préoccupés par l'impact économique de la pandémie que par la maladie elle-même. Selon les résultats d'une enquête Statistics-SA, 93,2\% des répondants (49\% d'entre eux des personnes blanches; 36\% d'Africains noirs) étaient très préoccupés ou extrêmement préoccupés par l'éventuel effondrement économique du pays dû à Corona (Githahu, 2020, Schwettmann , 2020).

\section{L'impact du Brexit sur l'Afrique du Sud}

Et là encore, le Brexit entre en jeu, car l'économie sud-africaine est fortement dépendante à la fois de l'UE et du Royaume-Uni, qui est devenu le quatrième marché d'exportation du pays. En 2018, les exportations de SA vers le Royaume-Uni se sont élevées à environ 64 milliards de rands, principalement des métaux précieux, des automobiles et des produits agricoles. Les importations de SA en provenance du Royaume-Uni ont atteint 43,5 milliards de rands. Néanmoins, l'UE est restée de loin le principal partenaire commercial. Le Royaume-Uni ne représentait que $18 \%$ des exportations sud-africaines de l'UE et $10 \%$ des importations de l'UE en provenance d'Afrique du Sud (Maeko, 2020). Par conséquent, le gouvernement de Pretoria et ses partenaires de l'Union douanière de l'Afrique australe (SACU), y compris des membres de la Communauté de développement de l'Afrique australe (SADC) et du Mozambique, ont fait tout leur possible pour maintenir des relations commerciales normales après le Brexit avec l'UE dans le cadre de leur accord de partenariat économique (APE) conclu déjà en octobre 2016. À l'époque, la Grande-Bretagne était encore membre de l'UE lié à l'APE également, qui stipulait que plus de $90 \%$ des produits sud-africains, y compris les vins, le platine et les véhicules à moteur, pourrait entrer au Royaume-Uni en franchise de droits ou partiellement en franchise. Cependant, parce que néanmoins les exportations de voitures de l'Afrique du Sud seraient toujours soumises à des droits de douane de $10 \%$, et parce que la chaîne d'approvisionnement mondiale dans la production automobile serait définitivement perturbée en cas d'une Brexit dure, l'industrie automobile du pays l'aurait été complètement "radié », selon l'ancien ministre du Commerce et de l'Industrie de Pretoria, Rob Davies (Maeko, 2020). Cela a été confirmé entre autres par VW-Afrique du Sud, dont le PDG a déclaré à la presse en août 2019 que si les composants de l'UE ne seraient plus inclus dans le calcul de la valeur ajoutée en raison d'un Brexit sans accord, les droits d'importation menaceraient dans les deux directions. Ils rendraient les voitures - selon le type - environ 1500 à 2000 euros plus chères (DPA (os) -2019). Cela aurait un impact énorme sur le marché du travail sud-africain, indépendamment des effets économiques démesurément plus graves d'une crise Corona mondiale.

Cependant, en général, les hommes d'affaires sud-africains étaient légèrement perplexes quant au divorce de leurs collègues européens. La plupart des perceptions sud-africaines sont encore enracinées dans leur vision du Nord global et de l'héritage du colonialisme et de l'apartheid. Les deux, le Royaume-Uni et l'UE, sont limités aux relations commerciales. Cela a conduit les Sud-Africains à interpréter le Brexit en grande partie sur des bases économiques, divisibles en trois catégories: le Brexit comme opportunité, le Brexit comme risque et le Brexit comme continuité. Cependant, en général, leur perception du Brexit était que cela affaiblissait très probablement le Royaume-Uni et non l'UE (Kotsopoulos, 2020). 


\section{(2) Nigeria, Brexit et Corona}

\section{L'impact du Brexit sur le Nigeria}

Le sommet sur l'investissement Royaume-Uni-Afrique à Londres en janvier 2020 a donné au premier ministre Johnson l'occasion d'expliquer sa vision d'un partenariat renforcé avec les pays africains à l'époque de l'après-Brexit. Cependant, le Nigeria et le Royaume-Uni ne sont pas de proches partenaires commerciaux. Le Nigeria représente moins de 0,5\% du commerce du Royaume-Uni et reçoit moins de 3 à $4 \%$ du commerce des marchandises du Nigeria. Au contraire, le commerce britannique est dominé par la Chine (15\%), les États-Unis (8\%), l'Inde (12\%) et les Pays-Bas (8\%), qui représentent également environ $40 \%$ du commerce total des marchandises du Nigeria (éditorial, Trafic commercial, 2020). De plus, le Nigeria poursuit une stratégie d'import-substitution et de «rattrapage-développement » et préfère donc renforcer lui-même son secteur manufacturier, plutôt que d'aider la Grande-Bretagne à relancer son secteur manufacturier et ses exportations dans le cadre d'une division de maind'œuvre postcoloniale où l'ancienne colonie servirait de fournisseur de matières premières, notamment le pétrole et les produits pétroliers qui représentent toujours $98 \%$ des exportations Nigerianes vers le Royaume-Uni. Désormais, le Nigeria propose d'étendre ses exportations agricoles au Royaume-Uni, qui languissait d'environ $2 \%$ jusqu'à présent, mais malheureusement, l'agriculture est probablement le dernier secteur auquel le Royaume-Uni ouvrirait ses frontières. Il préfère continuer à protéger ses agriculteurs comme il l'a fait dans le passé de la longue histoire du protectionnisme agricole commun entre le Royaume-Uni et l'UE dans le cadre de sa politique agricole commune. En 2019, Londres a déjà indiqué qu'en cas de Brexit sans accord, il réduirait près de $90 \%$ des droits de douane à zéro, en excluant, cependant explicitement, les produits agricoles tels que le bœuf et les produits laitiers, y compris le beurre que le Nigeria exporte au Royaume-Uni. Bien que Londres ait promis que les pays en voie de développement obtiendraient un accès préférentiel spécial au RoyaumeUni après le Brexit - comme c'est le cas dans l'UE maintenant - le Nigeria ne figurait pas sur la liste des pays africains tels que le Bénin, l'Angola et le Sénégal qui ont été étiquetés comme les pays en voie de développement auquel un tel traitement s'appliquerait (Editorial, Business traffic, 2020).

Concernant les investissements directs à l'étranger (IDE) et l'aide au développement, le fossé entre les promesses généreuses faites par Johnson et la réalité est moins prononcé. Le Royaume-Uni restera sans aucun doute l'un des principaux investisseurs étrangers du Nigeria. En 2018, il a contribué à plus de 35\% des investissements étrangers du Nigeria, qui s'élevaient à 6 milliards de dollars (Editorial, Business traffic, 2020). Lors du sommet sur l'investissement entre le Royaume-Uni et l'Afrique, Londres a annoncé des investissements de plus de 150 milliards de livres sterling dans des projets visant à améliorer l'infrastructure physique du Nigeria. Aujourd'hui, son département du développement international (DFID) a répertorié 46 projets actifs au Nigeria, allant de l'énergie solaire à l'aide humanitaire dans le Nord-Est, souffrant du terrorisme de Boko Haram.

Déjà deux ans auparavant, en août 2018, la Première ministre Theresa May, lors de sa tournée en Afrique du Sud, au Nigeria et au Kenya, se vantait de protéger les industries africaines naissantes avec sa politique post-Brexit contrairement aux accords de partenariat économique de l'UE (EPA; voir Kohnert, 2015). Le deuxième jour de sa tournée, par exemple, elle a dévoilé à Abuja (Nigeria) des propositions pour créer le premier partenariat de la La technologie financière (FinTech) Royaume-Uni-Afrique à Lagos. La Grande-Bretagne est une plaque tournante mondiale de premier plan pour la technologie financière (FinTech), qui 
contribue chaque année à plus de 5 milliards de livres sterling à l'économie britannique, et Lagos est réputé d'être à la pointe de l'innovation FinTech en Afrique. Les échanges entre le Royaume-Uni et le Nigeria représentaient 4,2 milliards de livres sterling l'année dernière, et des sociétés britanniques, notamment British Airways, GSK, Shell, Diageo, Unilever et Standard Chartered, ont des activités établies de longue date au Nigeria. Au total, 111 entreprises africaines sont déjà cotées à la Bourse de Londres. À Lagos, T. May a également rencontré le principal homme d'affaires Nigerian, Aliko Dangote, et s'est félicité de l'annonce de son engagement à inscrire sa société de ciment de 10 milliards de dollars à la Bourse de Londres (LES). Toujours en 2018, la société pétrolière et gazière Seplat Petroleum s'était engagée à inscrire son programme Eurobond de 350 millions de dollars sur le LSE (Little 2018).

Cependant, toutes ces promesses pourraient être difficiles à vendre. Au vu de la célèbre offensive africaine de longue date de la Chine, il est permis de se demander ce que la GrandeBretagne pourrait offrir, ce que les autres concurrents n'ont pas déjà à leur ordre du jour. Les dirigeants africains sont dans une position confortable pour choisir : une coopération renforcée avec la Chine, avec l'Union européenne, les États-Unis ou avec le Royaume-Uni historiquement lié. Très probablement, les Africains joueront un partenaire contre l'autre, choisissant le meilleur pour leur clientèle. Ainsi, ils seront bien conscients de l'importance relative de chaque partenaire commercial, qui n'agirait pas nécessairement en faveur du Royaume-Uni compte tenu de la position de négociation forte des principaux concurrents.

\section{L'impact de Corona sur le Nigeria}

Au Nigeria, pays le plus peuplé du continent (environ 180 millions), qui compte le plus grand nombre de personnes au monde vivant dans la pauvreté absolue (87 millions), la pandémie a commencé relativement tard et modérément, avec le premier cas confirmé le 27 février 2020 , d'un citoyen italien à Lagos. Le 9 mars seulement, un deuxième cas avait été signalé dans l'État d'Ogun d'un Nigerian en contact avec le citoyen italien. Selon les derniers chiffres disponibles, il y avait quatre cent quatre-vingt-dix nouveaux cas au 16 juin 2020.

\section{Carte 3: Propagation de Corona au Nigeria}

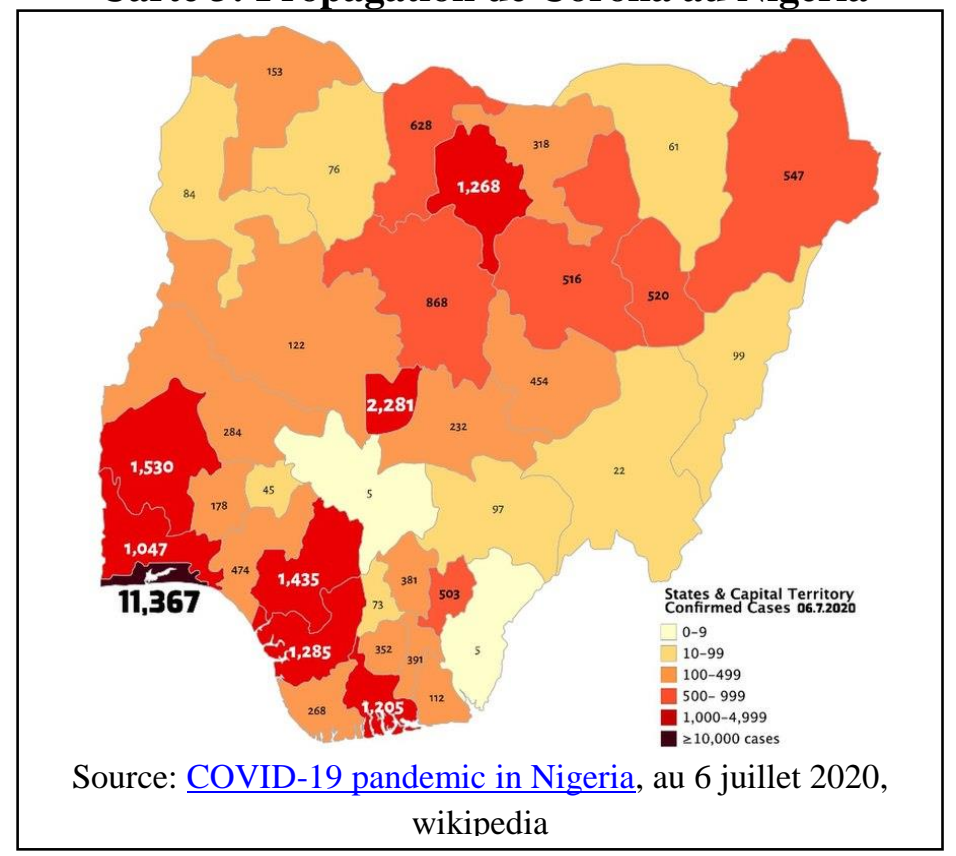


Les Nigerians se sont longtemps sentis invulnérables. Jusqu'au premier cas confirmé du 27 février, de nombreux Nigerians considéraient la pandémie plutôt comme un problème d'étrangers. L'expérience passée de la lutte réussie du Nigeria contre le virus Ebola en 2014 a peut-être contribué à un sentiment d'invulnérabilité. Corona a été banalisée par de nombreux Nigerians pauvres du vaste secteur informel Nigerian comme un fléau des riches et de l'élite ou comme une punition de Dieu pour les décennies de pillage du pays par l'élite au pouvoir et donc ils espéraient être sauvés du virus. Le gouvernement a réagi tard et a imposé un couvrefeu à Lagos et dans la capitale Abuja. Un peu plus d'un mois seulement après le signalement du premier cas Corona, le 29 mars, un couvre-feu a été imposé aux 20 millions de la métropole de Lagos et de la capitale Abuja. Il a été prolongé de deux semaines supplémentaires le lundi de Pâques. Les citoyens n'étaient autorisés à quitter leur domicile que pour se procurer les produits de première nécessité et les activités économiques ont diminué. Le trafic aérien international et national a été suspendu et les frontières nationales fermées. La liberté de réunion, y compris les rassemblements religieux, l'activité économique et la liberté de mouvement ont été restreintes dans la plupart des 36 états Nigerianes (Thum, 2020). Le 1er juin, le gouvernement fédéral a assoupli le verrouillage imposé à l'État de Kano et l'interdiction des rassemblements religieux et des opérations bancaires pour une période de quatre semaines et a également abrégé le couvre-feu de 22 heures à 4 heures du matin. Encore une fois, l'économie informelle du Nigeria, qui compte environ 56 millions de citoyens, a été le plus durement touchée par les mesures d'endiguement (Schwettmann, 2020: 10-11).

À l'heure actuelle, l'économie Nigériane est en baisse. Il y a à peine un an, le Nigeria était sorti d'une douloureuse récession. Désormais, les activités économiques ont été réduites sous les restrictions de sortie de Corona. La production, le commerce et la consommation étaient en baisse, de nombreux emplois formels convoités seront perdus et le secteur informel dominant manque de revenus. Les recettes publiques, qui proviennent des deux tiers du pétrole, souffrent de la baisse des cours mondiaux du pétrole brut, qui se situent actuellement entre 25 et 30 dollars le baril. Cependant, le gouvernement comptait toujours dans sa budgétisation avec 57 \$ US le baril. Cela pourrait entraîner un sous-financement du budget de près de 50\%. Les effets du Coronavirus entraîneront un énorme ralentissement de l'économie Nigériane dans tous les scénarios. En outre, le Nigeria est confronté à une pénurie de chaînes d'approvisionnement pour les matières premières destinées à la production et d'autres marchandises, car une grande partie des marchandises était bloquée dans les ports chinois (Thum, 2020).

Cependant, jusqu'à présent, la crise Corona a eu peu d'impact sur la stratégie gouvernementale relative au Brexit. Apparemment, le président Muhammadu Buhari et un grand nombre de Nigerians partageaient l'orgueil des Britanniques selon lequel ils sont moins vulnérables à la pandémie et pourraient continuer avec les plans post-Brexit de haut vol d'un nouvel accord avec le Royaume-Uni. Buhari partageait apparemment la vision de Johnson du commerce déchaîné au sein du Commonwealth et avec le Royaume-Uni. Le 20 janvier, il a affirmé dans un article intitulé «Un nouveau cas pour un Commonwealth fondé sur le commerce », que les relations bilatérales de longue date entre les deux pays avaient été confirmées entre autres par le pacte bilatéral de sécurité de 2018 et la collaboration dans la lutte contre la traite. Un nouvel accord de libre-échange présenterait de nouvelles opportunités pour les deux pays, notamment, parce que l'économie Nigeriane aurait beaucoup à offrir : les vastes ressources naturelles énergétiques et minérales du Nigeria, non bloquées par la suppression des barrières douanières, pourraient aider à fournir le stimulus de croissance indispensable pour les entreprises britanniques. Un meilleur accès au Royaume-Uni donnerait également une impulsion à l'un des groupes de consommateurs à la croissance la plus rapide au monde, avec un pouvoir d'achat considérable, la classe moyenne Nigeriane. D'un autre côté, l'engagement 
accru du Royaume-Uni dans l'économie Nigeriane créerait des emplois dans des secteurs sous-exploités, tels que l'agriculture et la fabrication. Des millions de jeunes Nigerians hautement qualifiés, anglophones, mais sous-employés, étaient désireux de travailler, mais jusqu'ici sans les opportunités que les investissements étrangers pouvaient offrir pour créer des emplois et créer des entreprises. Buhari a finalement suggéré qu'une coopération étroite serait particulièrement prometteuse, car les deux pays pourraient mieux aligner les réglementations sur l'investissement, la certification et le commerce, car les lois nationales des pays membres étaient fondées sur les mêmes principes de la jurisprudence anglaise. D'un autre côté, il a averti que, si de nombreux Nigerians de la diaspora africaine bénéficient d'avantages considérables à vivre en Occident, ils ne se sentent pas toujours au cœur de la communauté de leur pays d'accueil. Par conséquent, les restrictions de visa et les barrières douanières devraient être réduites (Olaniyi, 2020). Les Nigerians de la Commission de la diaspora (NIDCOM) ont même vu le Brexit comme une opportunité pour le Nigeria d'exploiter le capital humain pour son développement au Royaume-Uni. Selon eux, le Nigeria devrait y contribuer en envoyant des délégations commerciales en Grande-Bretagne pour ramener ses investissements dans le capital humain chez lui (Taiwo-Obalonye, 2020).

Cependant, la demande de lever des restrictions de visa pour les Nigerians rencontrera peu de réponses de la part de Johnson et des travailleurs britanniques qui auraient vraisemblablement peur de la " concurrence déloyale » des nombreux travailleurs Nigerians informels et mal payés dans leur pays et de la mauvaise réputation de ces derniers en tant que trafiquants de drogue et criminels. Actuellement, jusqu'à 300000 Nigerians et Britanniques d'origine Nigeriane résident en Grande-Bretagne. Beaucoup d'entre eux avaient apparemment déjà peur d'une réaction contre les immigrants en Grande-Bretagne dans laquelle les Nigerians et d'autres étrangers seraient visés après l'époque post-Brexit, lorsque les Britanniques ont eu leur souhait d'endiguer la marée d'immigrants en Grande-Bretagne (N.A., 2020).

\section{(3) Ghana, Brexit et Corona}

\section{L'impact du Brexit sur le Ghana}

L'impact économique du Brexit sur le Ghana sera le plus grave dans le commerce, les investissements directs étrangers (IDE) et les migrations (envois de fonds). Les effets politiques indirects pourraient inclure la perte d'un ardent défenseur au sein de l'UE, car le Royaume-Uni ne façonnerait plus et ne dirigerait plus certaines des initiatives les plus importantes du continent africain qui forment la base de la coopération entre l'Europe et le continent (Ghanaian Times Éditorial, 2020; Appiah-Kubi, 2019). De plus, l'accord de partenariat économique (APE) intérimaire signé en août 2016 par le Ghana qui autorisait l'exportation de marchandises vers l'UE, y compris le Royaume-Uni, sans contingent et sans paiement de droits de douane, devrait être renégocié par Londres, en cas d'un Brexit sans accord. Pour éviter les perturbations, le Ghana pourrait rejoindre des pays tels que ceux du Marché commun de l'Afrique orientale et australe (COMESA, composé de 21 pays, dont le Kenya, l'Égypte, l'Éthiopie et le Rwanda) qui ont signé un accord avec le Royaume-Uni pour profiter de certaines concessions tout comme ils en bénéficient dans le cadre de l'APE (Appiah-Kubi, 2019).

Jusqu'à présent, les exportations du Ghana vers le Royaume-Uni se sont élevées à 329,47 millions de dollars après avoir successivement diminué d'environ 350 millions de dollars en 2011, et ses importations à 1,1 milliards de dollars (2017, derniers chiffres disponibles; 
Appiah-Kubi, 2019). On peut se demander si le Ghana pourrait remplacer une partie importante de la perte potentielle par une délocalisation de son commerce vers la nouvelle zone de libre-échange continentale africaine (ZLEC). Cependant, comme les exportations ghanéennes vers le Royaume-Uni ne représentaient qu'environ $2 \%$ des exportations totales du Ghana (et environ 6,3\% des importations) en 2017, la perte potentielle due au Brexit devrait être supportable. À moyen terme, le Brexit pourrait affaiblir les échanges entre le RoyaumeUni, l'UE et l'Afrique, y compris le Ghana, car Londres devrait renégocier de nouveaux accords commerciaux avec le Ghana et la CEDEAO, ce qui sera coûteux et prend du temps. En ce qui concerne les IDE, la Grande-Bretagne s'est classée au cinquième rang des sources au Ghana, avec une valeur totale de 87,1 millions de dollars américains en 2018 (AppiahKubi, 2019). La contraction probable de l'économie britannique en raison des effets combinés du Brexit et de Coroana entraînera un ralentissement significatif des investissements britanniques au Ghana. Cet effet négatif sera accentué par une réduction probable des envois de fonds. Désormais, la pression exercée sur Johnson pour qu'il délivre, pourrait entraîner de nouvelles restrictions des visas et des visites des Ghanéens autorisés à entrer au RoyaumeUni, ce qui aurait également un impact négatif sur les envois de fonds, qui s'élevaient à un total de 1,97 milliards de dollars américains pour le Ghana en 2017, dont 21,82. \% (429,5 millions de dollars américains) de Grande-Bretagne (Appiah-Kubi, 2019 ; Hawkson, 2019).

\section{L'impact de Corona sur le Ghana}

Au 15 août, le Ghana comptait avec 42993 cas de COVID-19 infections signalés parmi les trois principaux «propagateurs» du virus Corona en Afrique subsaharienne, à côté de l'Afrique du Sud (101 590) et du Nigeria (2,091).

La répartition par sexe des cas de Corona est inégale avec beaucoup plus d'hommes (59\%) infectées que de femmes (41\%) (Source: Ghana Health Service, Accra, 25 juin 2020).

Figure 1: nouveaux cas quotidiens de COVID-19 au Ghana, mars à juin 2020

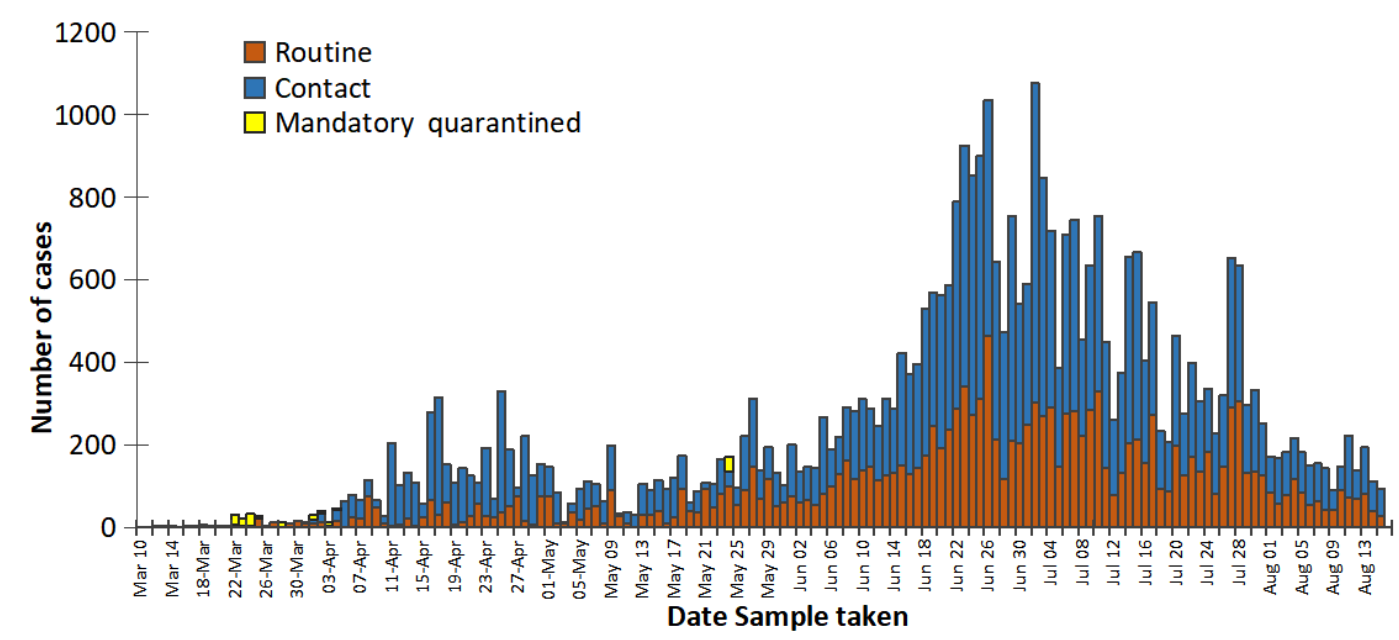

Figure 1: Distribution of COVID-19 cases in Ghana by date sample taken, March - August 2020

Source: mise à jour de la situation, épidémie de COVID-19 au Ghana au 15 août 2020

Ghanian Health Service, Accra

L'évolution des cas de COVID-19 ainsi que le nombre de décès au Ghana de mars à juin 2020 sont illustrés dans les figures 1 et 2. 
Figure 2: Nombre total de décès par Coronavirus au Ghana, février à juin 2020 (échelle linéaire, moyenne mobile sur 6 jours)

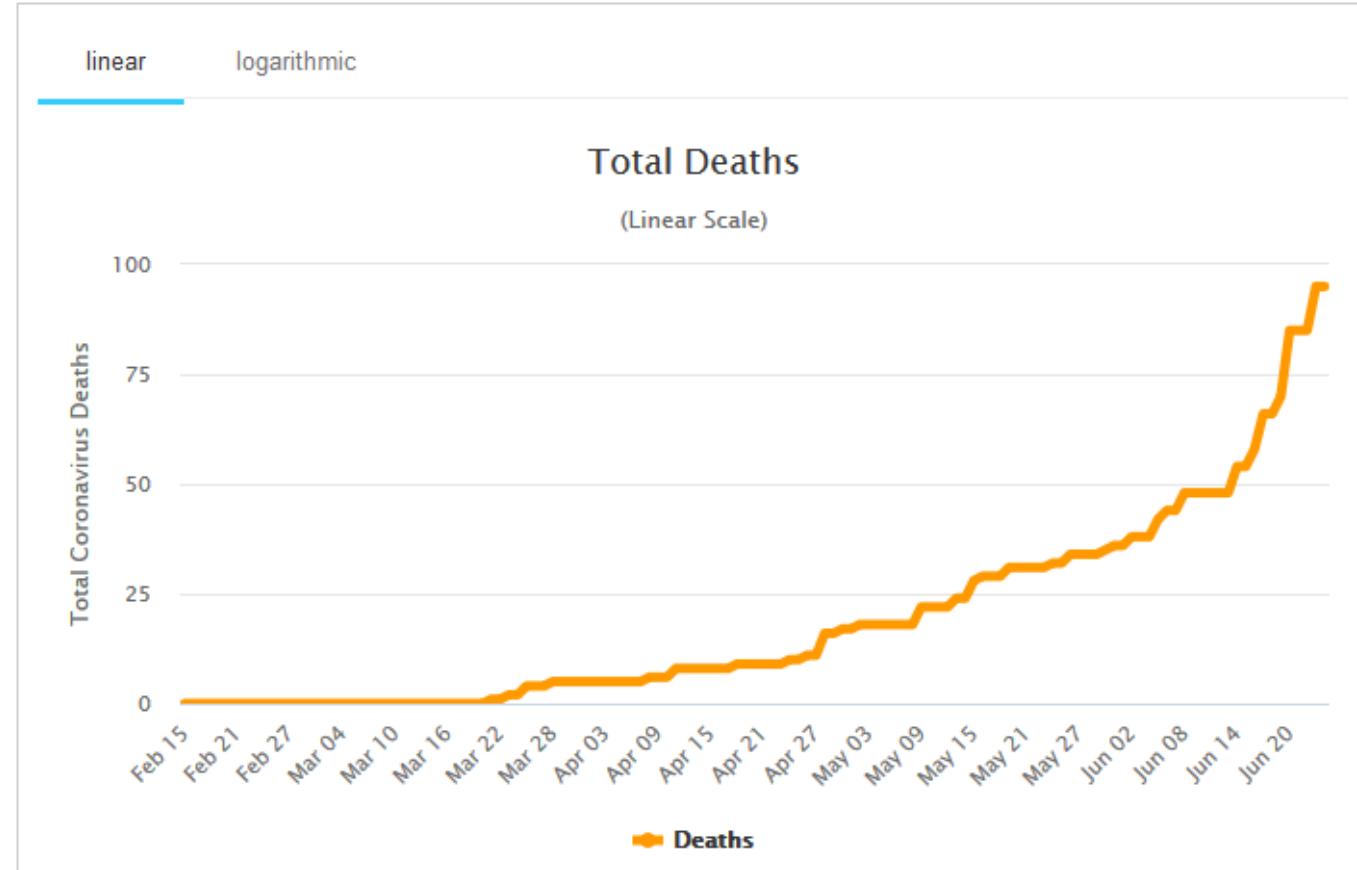

Source: Worldometer, Coronavirus, pays, Ghana, au 25 juin 2020

Quant à la répartition régionale des cas, la plupart sont concentrés dans les zones urbaines du Grand Accra et des capitales d'Ashanti et de la région occidentale (graphique 6, tableau 1).

\section{Graphique 6: Répartition régionale des cas confirmés de COVID-19 au Ghana} au 25 juin 2020

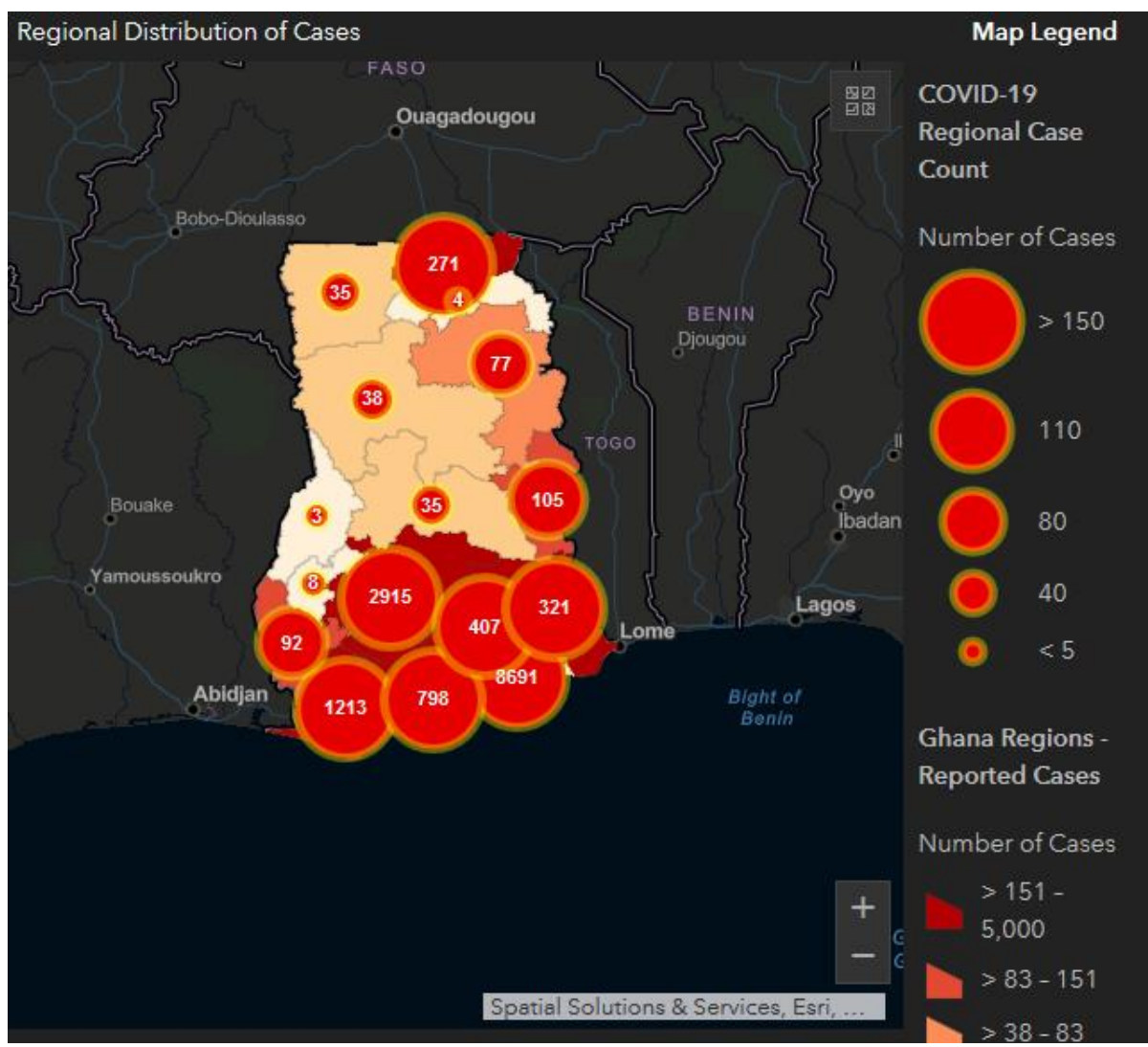

Source: Mise à jour de la situation, épidémie de COVID-19 au Ghana au 25 juin 2020 
Une étude détaillée récente du ministère des Finances à Accra sur l'impact attendu de l'épidémie de COVID 19 sur l'économie ghanéenne et les finances du gouvernement a abouti à une perspective sombre, bien que le pic de la pandémie n'ait apparemment pas encore été atteint. Il y aura vraisemblablement un ralentissement significatif de la croissance du PIB, induit entre autres par d'importantes déficits des recettes pétrolières, des droits d'importation et d'autres recettes fiscales, une augmentation des dépenses de santé et des conditions de financement plus strictes (Équipe 1, 2020).

L'étude a fait la distinction entre les effets directs et indirects: directement, la pandémie a un impact significatif sur la production et le commerce nationaux ainsi que sur le commerce et les investissements internationaux, notamment avec la Chine, principale source d'importations du Ghana et deuxième destination des exportations du Ghana, mais également sur le commerce avec l' Europe et les États-Unis. De plus, elle aura un impact sur les prix mondiaux des matières premières (pétrole brut, l'or et le cacao), baisse significative du prix international du pétrole brut en raison de la baisse de la demande (en particulier en Chine). Le prix du pétrole brut est déjà passé de 63,21 \$ US le baril en novembre 2019 à 22,9 \$ US le baril au 30 mars 2020. De plus, les prix du cacao sont passés de 2440 MT \$ US en décembre 2019 à 2 253 MT \$ US au 30 mars, 2020. Cependant, la demande accrue d'or en tant que valeur refuge aura probablement un impact positif sur la balance des paiements et les recettes provenant des redevances minières. Le prix de l'or est passé de 1479 \$ US / toz en décembre 2019 à 1621,6 \$ US / toz, soit une augmentation de 9,6\% au 30 mars 2020 (Équipe 1, 2020). Indirectement, le ralentissement général de l'économie mondiale et la perturbation des chaînes d'approvisionnement auront également un impact négatif sur l'économie du Ghana.

Tableau 1: Répartition régionale des cas confirmés de COVID-19, récupérations et renvois Ghana, 21 juin 2020

\begin{tabular}{|c|c|c|c|}
\hline Region & Cases & $\begin{array}{l}\text { Recovered/ } \\
\text { Discharged }\end{array}$ & $\begin{array}{c}\text { \% Recovered/ } \\
\text { Discharged }\end{array}$ \\
\hline Ahafo & 8 & - & - \\
\hline Ashanti & 2,867 & 1,887 & 66 \\
\hline Bono & 3 & 1 & 33 \\
\hline Bono East & 33 & 16 & 48 \\
\hline Central & 794 & 660 & 83 \\
\hline Eastem & 400 & 223 & 56 \\
\hline Greater Accra & 8,407 & 6,485 & 77 \\
\hline Northem & 61 & 61 & 100 \\
\hline North East & 3 & 2 & 67 \\
\hline Oti & 105 & 32 & 30 \\
\hline Savarmah & 37 & 37 & 100 \\
\hline Upper East & 271 & 23 & 8 \\
\hline Upper West & 35 & 35 & 100 \\
\hline Volta & 314 & 281 & 89 \\
\hline Westem & 1,148 & 1,099 & 96 \\
\hline Westem North & 82 & 65 & 79 \\
\hline TOTAL & 14,568 & 10,907 & 75 \\
\hline
\end{tabular}

Source: Mise à jour de la situation, flambée de COVID-19 au Ghana au 21 juin 2020 Service de santé ghanéen, Accra 
L'effet économique combiné du Brexit et de la Corona sur le Ghana sera une diminution substantielle de la croissance économique et du bien-être du peuple ghanéen. Comme d'habitude, l'impact négatif global se fera sentir durement, non seulement en ce qui concerne l'orientation budgétaire, mais aussi sur la vie humaine, en particulier la santé et la vie des pauvres et des vulnérables.

\section{(4) Kenya, Brexit et Corona}

La pandémie Corona a commencé au Kenya le 15 mars avec les premiers cas signalés dans la capitale Nairobi et la zone côtière de Mombasa. Bien que le taux de létalité pour le COVID19 ait été beaucoup plus faible que pour la pandémie de SRAS de 2003, la transmission du virus COVID-19 avait été significativement plus élevée, y compris un nombre total de décès important (Ministère de la Santé, Nairobi, Kenya). La dernière mise à jour du COVID-19 (16 juin 2020) a révélé un total de 3,860 cas confirmés et 105 décès. En avril, la répartition suivante des 133 cas positifs signalés était la suivante: à Nairobi (86 cas), Mombasa (27),

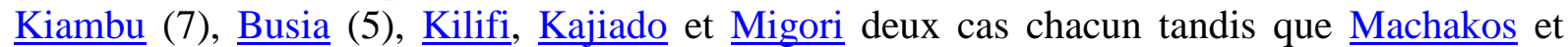
Muranga, avaient chacun un cas. Le Comité national d'intervention d'urgence du Kenya a imposé des exigences de distanciation sociale, fermé les bars et interdit les rassemblements religieux. Les restaurants devaient rester ouverts uniquement pour le service à emporter. Un couvre-feu quotidien, effectif à partir du 27 mars, à partir de 19 heures. à 5 heures du matin était en vigueur dans tout le pays. Le soir même où le couvre-feu avait été annoncé, les policiers de Mombasa pourchassaient les navetteurs qui n'étaient pas rentrés chez eux à temps. Ils ont fait déguerpir des hommes, des femmes et des enfants avec des gaz lacrymogènes et des matraques, le gouvernement a pardonné l'action (Starzmann, 2020).

Tableau 2: Propagation de Corona au Kenya

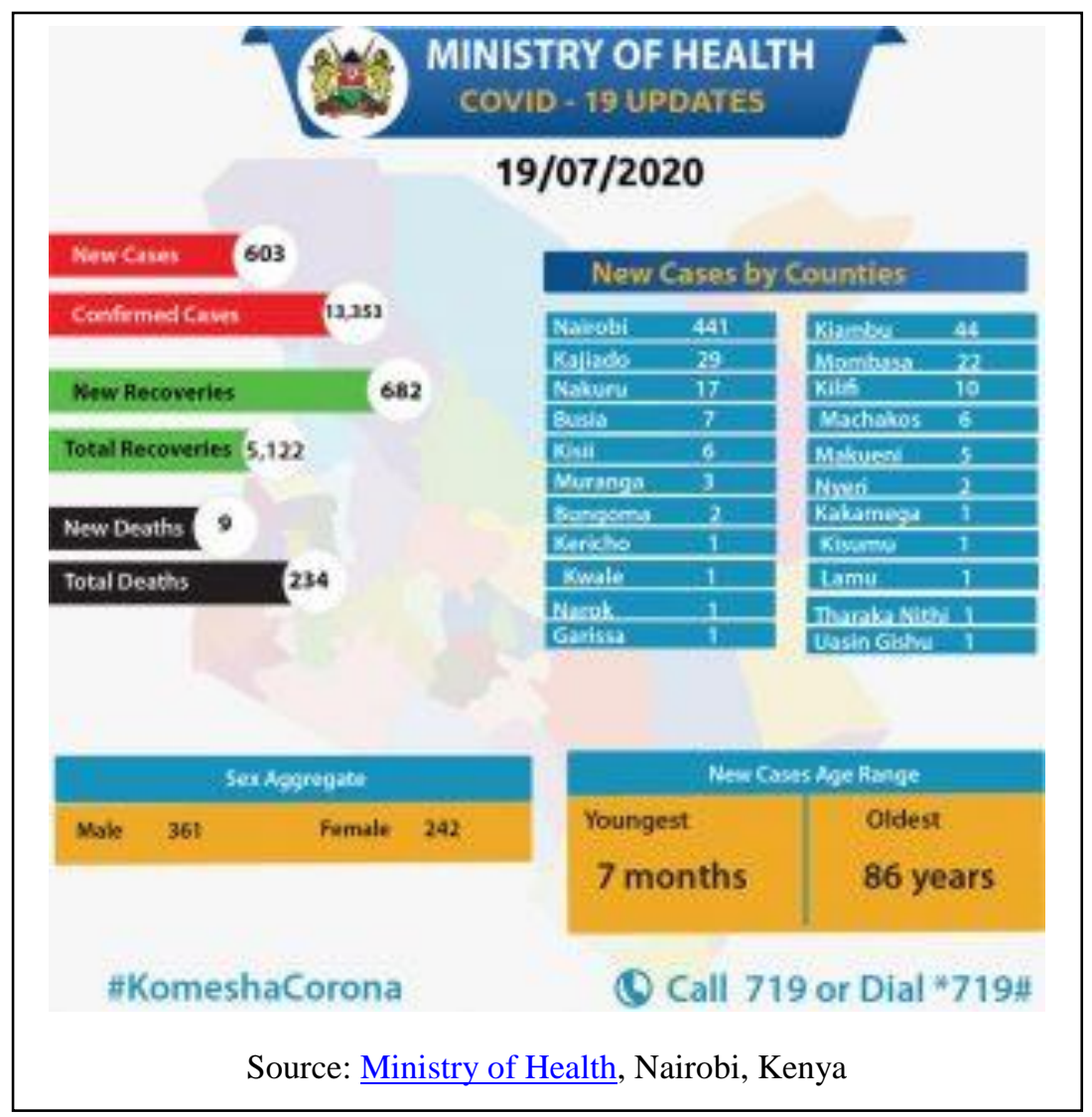


Le 16 juin, le gouvernement a prolongé les heures de fermeture des restaurants et des hôtels de $17 \mathrm{~h} 00$ à $19 \mathrm{~h} 30$ tous les jours avec un avertissement sévère que ceux qui enfreignent la loi verront leur licence d'exploitation révoquée (Ministère de la Santé, Nairobi, Kenya). Début mai, le FMI a approuvé un prélèvement de 739 millions de dollars US au titre de la facilité de crédit rapide pour soutenir la réponse des autorités à la pandémie de COVID-19. L'augmentation des cas de COVID-19 a incité le gouvernement à déclarer un verrouillage dans la région d'Eastleigh et de la vieille ville de Nairobi à Mombasa (Market Watch, 2020).

Fin mars, le gouvernement kényan a imposé un couvre-feu nocturne pour contenir la pandémie. Comme dans la plupart des pays africains, les plans de sauvetage mis en place par le gouvernement de Nairobi excluent largement le secteur informel. Plus de $80 \%$ des Kenyans travaillent comme journaliers. Le couvre-feu nocturne, les bars et restaurants fermés signifient déjà que beaucoup ne gagnent plus rien (DW, 2020). Cela impliquait de graves conséquences économiques, sociales et sécuritaires étant donné le grand nombre de femmes, de jeunes et de travailleurs défavorisés. Le secteur informel est l'espace de survie de la majorité des 800000 jeunes demandeurs d'emploi au chômage qui entrent chaque année sur le marché du travail kényan. Les emplois dans ce secteur sont précaires, avec des salaires et une sécurité d'emploi limités, un accès limité aux services de santé et à la protection sociale, y compris des cadres faibles pour la sécurité et la santé au travail. Cela rend les travailleurs très exposés aux pertes de revenus et aux licenciements dus aux chocs COVID-19 (Omolo, 2020; Schwettmann, 2020: 9-10).

Apparemment, la pandémie Corona a eu jusqu'à présent peu d'impact sur l'opinion du Kenya sur la question du Brexit. De nombreux Kényans ont vu le départ du Royaume-Uni de l'UE comme une bénédiction déguisée, car les investisseurs britanniques rechercheraient vraisemblablement des pays en forte croissance comme le Kenya qui pourraient à la fois commercer avec le Royaume-Uni et qui ne seraient pas non plus affectés par les restrictions imminentes de l'UE pour le Royaume-Uni (Hopkins, 2020). Cependant, l'immigration de pays extérieurs à l'UE comme le Kenya vers le Royaume-Uni deviendrait plus difficile. Après tout, l'attitude anti-immigration était à l'origine de la désaffection de nombreux électeurs du Brexit. Le lobby anti-immigration était essentiellement raciste. D'un autre côté, au moment même où le Royaume-Uni était le plus durement touché par la pandémie, le Service national de santé britannique a désespérément besoin de personnel médical tel que des infirmières dont le Kenya était une source depuis des années. Mais ce sera plus difficile à réaliser maintenant. Londres devrait fixer ses priorités, elle devra d'abord renégocier au moins 700 accords commerciaux avec les 27 pays européens, que le Kenya obtienne la priorité est plutôt improbable (Hopkins, 2020).

De plus, avec le scénario post-Brexit, le Kenya courrait le risque de perdre des affaires avec les deux partenaires, l'UE et le Royaume-Uni. Jusqu'à présent, le Royaume-Uni faisait partie de près de 40 accords commerciaux que l'UE a conclus avec plus de 70 pays. Les exportations du Kenya vers l'UE sont passées de 125,61 milliards de shillings en 2018 à 131,20 milliards de shillings en 2019. Alors que les exportations du Kenya vers le Royaume-Uni n'ont augmenté que de 38,55 milliards de shillings à 40,19 milliards de shillings au cours de la même période. Les importations en provenance du Royaume-Uni et de l'UE ont augmenté pour atteindre 31,55 milliards de shillings et 219,60 milliards de shillings respectivement en 2018 (Kivuva, 2019).

Jusqu'à présent, les principaux problèmes entravant la croissance des PME kényanes étaient l'accès limité au financement et la lenteur de l'intégration des technologies les plus récentes, ainsi que la méconnaissance des normes internationales et de l'assurance de la qualité, et le 
manque de recherche et d'innovation sur les nouveaux produits. Tout cela empêcherait le pays de concurrencer au niveau du marché mondial (Kivuva, 2019). Cependant, le gouvernement kényan restait convaincu que le Commonwealth fournirait une assistance et des innovations liées au commerce à la zone de libre-échange par le biais de financements pour accélérer les transactions et accroître l'efficacité. Selon le secrétaire général du Commonwealth, Patricia Scotland, les pays du Commonwealth bénéficient d'un avantage de coût de $19 \%$ par rapport à des paires de pays comparables. Selon ses visions de haut vol, le commerce et les investissements intra-Commonwealth devraient augmenter à 202,6 billions de shillings (2 billions de dollars) d'ici 2030. Juste à titre de comparaison, en 2017, le commerce des biens et services était d'environ 56,7 billions de shillings ( 560 milliards de dollars américains; Kivuva, 2019). En janvier 2020, le Premier ministre Johnson a salué les relations commerciales avec le Kenya, lorsqu'il a positionné le Royaume-Uni, lors du Sommet sur l'investissement Royaume-Uni et Afrique à Londres, comme un partenaire d'investissement important pour l'Afrique après le Brexit. Il a cité l'investissement de 53 millions de dollars de son pays dans le port de Mombasa en 2013 comme exemple de relation bénéficiant à toutes les parties concernées. De plus, le Kenya, sous la direction de son président Uhuru Kenyatta, a obtenu des contrats sur plus de 170 milliards de shillings d'investissements pendant le sommet dans des secteurs tels que le logement et l'entrepreneuriat. En outre, la première obligation verte du pays a été cotée à la Bourse de Londres. Enfin, le producteur d'alcool Diageo a promis d'investir 21,9 milliards de shillings pour construire des brasseries respectueuses de l'environnement au Kenya et en Afrique de l'Est au sens large. L'entreprise avait déjà investi 14 milliards de shillings dans une usine de fûts de Kisumu (Wambu, 2020). Cependant, les observateurs kényans ont déjà averti que si l'économie britannique s'effondrait à la suite d'un Brexit mal planifié, un double coup dangereux frapperait les exportateurs kényans. Il y aurait moins à vendre et un tarif plus élevé à payer pour le privilège d'appartenir au Commonwealth post-Brexit. Par conséquent, le Kenya serait bien avisé de s'aligner avec des partenaires du monde entier (Munuhe, 2019).

\section{Conclusion}

Bien que la Grande-Bretagne ait été jusqu'à présent la plus durement touchée par la pandémie de Corona parmi les États membres de l'UE, et qu'une deuxième vague de Corona plane déjà sur le Royaume-Uni, qui menace d'aggraver encore plus l'impact économique de la pandémie sur l'île, le Premier ministre britannique Boris Johnson persiste à quitter l'UE à la fin de 2020, quel qu'en soit le coût. Le produit intérieur brut (PIB) mensuel a chuté de $20,4 \%$ en avril 2020, la plus forte baisse que le Royaume-Uni ait jamais connue, plus de trois fois plus importante qu'en mars et presque dix fois plus importante que la plus forte baisse pré-COVID19. Dans ces conditions, il est déjà douteux que le Royaume-Uni soit capable de se sortir de la crise Corona après le Brexit sans la coopération éprouvée avec l'UE. Il est encore plus improbable que la Grande-Bretagne, à elle seule, ait le pouvoir supplémentaire d'aider ses anciennes colonies africaines à faire face non seulement aux conséquences de la pandémie Corona, mais aussi à l'impact d'un Brexit sans accord. Dans ces conditions, on peut s'attendre à ce que Londres soit plus que jamais désireuse de profiter d'un éventuel plan de sauvetage commun de l'UE pour les années à venir, tant pour les conséquences économiques que sanitaires de la pandémie. Cela est d'autant plus vrai, en raison des effets négatifs supplémentaires probables du Brexit sur l'emploi. Cependant, Johnson ne semble pas s'en soucier. Et on peut se demander si ceux qui ont voté le Premier ministre au pouvoir agiraient maintenant autrement. En fait, certains politiciens se sont déjà aventurés à deviner, le 
gouvernement britannique pourrait provoquer une sortie chaotique sans accord de l'UE pour détourner l'attention de son échec dans la crise COVID 19 (Mason, 2020).

Cependant, de nombreuses questions restent ouverts, notamment sur l'effet global du Brexit par rapport à l'impact mondial de la crise Corona. Vraisemblablement, ce dernier aura un impact beaucoup plus important sur le commerce international, en particulier avec l'Afrique. En outre, le poids relatif du Royaume-Uni par rapport à d'autres acteurs mondiaux comme la Chine et l'Inde, et même l'UE, diminuera à moyen et long terme. Et après tout, le nouvel axe mondial du commerce international sera réaffecté de l'Atlantique (Amérique et Europe) à la région Asie-Pacifique, l'acteur clé de l'économie mondiale à venir.

En Afrique subsaharienne, l'Afrique du Sud a sans doute été le pays le plus durement touché par le Brexit et la Corona. Cependant, la plupart des citoyens, notamment les pauvres, travaillant principalement dans le secteur informel, étaient plus préoccupés par l'impact économique de la pandémie que par la maladie elle-même. Cependant, les effets combinés du Brexit et de la Corona sont susceptibles d'avoir un impact considérable, notamment sur l'industrie automobile et le marché du travail sud-africain, indépendamment des effets économiques excessivement plus graves d'une crise mondiale de Corona.

Au Nigeria, le pays le plus peuplé du continent, la pandémie a commencé relativement tard et modérément, bien que la plupart des gens vivent dans une pauvreté absolue. Au début, ce dernier envisageait Corona comme un fléau des riches et de l'élite et comme le châtiment de Dieu pour les décennies de pillage du pays et ils espéraient être épargnés par le virus. Les activités économiques ont été réduites en raison des restrictions de sortie de Corona. La production, le commerce et la consommation étaient en baisse, la plupart des emplois formels convoités seront perdus et le secteur informel dominant manque de revenus. Le président Buhari et un grand nombre de Nigérians ont partagé l'orgueil des Britanniques selon lesquels ils sont moins vulnérables à la pandémie et pourraient continuer avec les plans post-Brexit de haut vol d'un nouvel accord avec le Royaume-Uni, y compris le commerce libéré au sein du Commonwealth et avec la Grande-Bretagne.

Le Ghana compte parmi les pays d'Afrique subsaharienne qui ont été les plus durement touchés par la pandémie Corona. Comme en général dans le monde entier, la répartition par sexe de Corona est inégale avec beaucoup plus d'hommes infectés que de femmes. Mais contrairement à l'Afrique du Sud et au Nigeria, les effets directs de la pandémie sur le ralentissement de son économie ne sont pas aussi importants que dans d'autres États africains en raison de sa base de ressources favorable et des mesures anti-Corona efficaces du gouvernement.

Au Kenya, le taux de létalité pour le COVID-19 avait été bien inférieur à celui de la pandémie de SRAS de 2003, mais la transmission du virus COVID-19 avait été significativement plus élevée, y compris un nombre total de décès significatif. Néanmoins, de nombreux Kényans ont vu le départ du Royaume-Uni de l'UE comme une bénédiction déguisée, car les investisseurs britanniques rechercheraient vraisemblablement des pays en forte croissance qui pourraient à la fois commercer avec le Royaume-Uni et ne seraient pas non plus affectés par les restrictions imminentes de l'UE pour le Royaume-Uni.

En un mot, il est clair et sans aucun doute que ceux qui souffriront le plus des effets combinés de la pandémie Corona et du Brexit en Afrique (et probablement dans le monde) sont les pauvres et les nécessiteux. 


\section{Bibliographie}

Aniche, E. T. (2019): The Brexit: A massive setback for European Union and a lesson for African integration. Chinese Political Science Review, Received: 29 May 2019

Appiah-Kubi, Kojo (2019): Brexit And Its Potential Impact On Ghana. Accra: Modern Ghana (MG), September 5, 2019

Bavier, Joe and Giulia Paravicini (2020): Africa could lose 20 million jobs due to pandemic: AU study. London: Reuters, 5 April 2020.“

Booth, Robert and Caelainn Barr (2020): Black people four times more likely to die from Covid-19. London: The Guardian, 7 May 2020

Breinlich, Holger et al (2020): Voting with their money: Brexit and outward investment by UK firms. European Economic Review, Volume 124, May 2020, https://doi.org/10.1016/j.euroecorev.2020.103400

Brugner, Philipp \& Klaus Schuch (2020): The EU's global response to the COVID-19 crisis with a focus on the Eastern Neighbourhood and Africa. Vienna: Österreichische Gesellschaft für Europapolitik, ÖGfE Policy Brief, 13'2020, 3 June 2020

Campbell , Denis et al (2020): Calls for inquiry as UK reports highest Covid-19 death toll in Europe. London: The Guardian, 5 May 2020

Colantone, Italo \& Piero Staning (2018): Global Competition and Brexit. American Political Science Review, 112(2), pp. 201-218

DPA (OS) (2019): Mögliche Folgen eines No-Deal-Brexit werden weltweit mit Sorge gesehen. Auch VW South Africa würde es wohl hart treffen. Automobilwoche, 31 August 2019

DW (2020): Brexit-Übergangsphase länger als gedacht?. Bonn: Deutsche Welle (radio)

Edgerton, David (2020): British exceptionalism: Where Brexit and our Coronavirus response collide. London: The New European, 3 May 2020

(Editorial, 2020): The Impact of Brexit on Nigeria. Lagos: Business traffic, The editor, January 31, 2020

English, Otto (2020): Cruel Britannia: Coronavirus lays waste to British exceptionalism. Politico.eu, May 5, 2020

Giles, Christopher \& Peter Mwai (2020): Coronavirus - How fast is it spreading in Africa ? London: BBC Reality Check, 14 August 2020

Ghanaian Times Editorial: Post- BREXIT, what is in it for Ghana and Africa? Accra: : Ghanaian Times Tuesday, 4 February 2020

Githahu, Mwangi (2020): Stats SA: More concerned about Covid-19 impact on economy than virus itself. Cape Town: IOL, Independent Media (Pty) Ltd, May 5, 2020

Gutteridge, Nick (2016): Africa waits for UK's Brexit. London: Black Economics, Sept.22, 2016

Haldane, Andy (2020) Numeracy skills are vital as we emerge from the Coronavirus crisis. London: The Guardian, 13 May 2020

Hassan,T.A. \& S. Hollander \& L. van Lent \& A. Tahoun (2021): The global impact of Brexit uncertainty. Cambridge M.A., National Bureau of Economic Research, NBER WP 26609, Revised March 2021

Hawkson, Emmanuel Ebo (2019): The effect of Brexit on Ghana. Accra: Daily Graphic, Aug 15, 2019 
Helm, Toby \& Robin McKie (2020): No-deal Brexit could wreck UK's chance of leading Covid-19 global research. London: The Guardian, 3 May 2020

Hollington, Marcus (2020): South Africa's world-class fight against Covid19: The data tells the story. Sandown: 947-radio, Sandown, Gauteng

Hopkins, Michael (2020): Here is what BREXIT means for Kenya. Nairobi: Standard digital, 2 February, 2020

Kennedy, Merrit (2020): World Bank: Coronavirus Is Pushing Sub-Saharan Africa To First Recession In 25 Years. npr.org, April 9, 2020

Kivuva, Elisabeth (2019): Kenya keenly watching Brexit move - Munya. Nairobi: The Star, 29 May 2019

Kohnert, Dirk (2018): More equitable British post-Brexit Africa relations: doomed to fail?, Africa Spectrum, vol. 53., No. 2, pp. 119-130 ;

Kotsopoulos, John (2020): South African perceptions of the EU and UK after Brexit. Chapter IN: Chaban, Natalia \& Arne Niemann \& Johanna Speyer (eds.): Changing Perceptions of the EU at Times of Brexit. London: Routledge: 2020, 17 pages

Laporte, Geert (2020): Europe-Africa relations after Corona. Brussels: European Think Tanks Group (ETTG) / ECDPM, 6 April 2020.

Little, Alison (2018), May forges African alliance as London prepares for deeper ties with Nigeria after Brexit. London: Express (Daily and Sunday Express, newspaper), August 29, 2018.

Maeko, Thando (2020): Is SA ready for Bojo's no-deal Brexit? Mail \& Guardian, SA, 22 Aug 2019

Mangisa, S. \& Das, S. \& Gupta, R. (2020): Analysing the Impact of Brexit on Global Uncertainty Using Functional Linear Regression with Point of Impact: The Role of Currency and Equity Markets. The Singapore Economic Review.

Marbot, Olivier (2020): L'Afrique face au Coronavirus : trois infographies pour mieux comprendre l'épidémie. Jeune Afrique, 25. March 2020

MarketWatch (2020): IMF Approves Sh78.3 Billion for Kenya to Address Covid-19 Pandemic. Nairobi: MarketWatch.com, May 7, 2020

Mason, Paul (2020): Inszenierte Eskalation Die britische Regierung provoziert womöglich einen chaotischen EU-Austritt ohne Deal, um von ihrem Versagen in der Covid-19-Krise abzulenken. ipg-journal, 22 May 2020

Munuhe, Faith (2019): Post Brexit, Kenya can take positive approach to grow its potential. Nairobi: Standard digital, 28th Jun 2019

N.A. (2020): Post Brexit Britain and Nigeria, Abuja: Daily Trust, (N:A.) no author given, Feb 10, 2020

NDP (2020): Covid-19 online resource and news portal. Pretoria: National Department of Health, South Africa

Nubong, Gabila (2019): Brexit and European Union Disintegration : lessons for Africa's integration. Africa Growth Agenda, Vol. 16, No. 4

Olaniyi, Muideen (2020): Brexit: We want new deal with UK - Buhari. Abuya: Daily Trust, Jan 20, 2020

Omolo, Jacob (2020): How the Pandemic is affecting the informal sector in Kenya. Nairobi: FES-Blog , Friedrich Ebert Stiftung, 20 April 2020

ONS (2020): GDP monthly estimate, UK: April 2020. London: Office of National Statistics 
Pelz, Daniel (2020): Coronavirus crisis disrupts flow of money transfers to Africa. Bonn: Deutsche Welle (DW), 23. May 2020

Ross Brown, Jose Liñares-Zegarra \& John O. S. Wilson (2019) The (potential) impact of Brexit on UK SMEs: regional evidence and public policy implications, Regional Studies, 53:5, 761-770, DOI: $10.1080 / 00343404.2019 .1597267$

Schwettmann, Jürgen (2020): Covid-19 and the informal economy. Impact and response strategies in Sub-Saharan Africa. Berlin: Friedrich Ebert Stiftung (FES), August 2020

Starzmann, Paul (2020): Ewiger Krisenkontinent? Wie afrikanische Politiker in der Coronakrise alte Klischees widerlegen. Berlin: Der Tagesspiegel, 11 May 2020

Taiwo-Obalonye, Juliana (2020): Brexit opportunity to harness human capital in Diaspora NIDCOM. Abuja: The Sun, Nigerian, 6th February 2020

Team 1 (2020): The economic impact of Coronavirus on Ghana's economy. Accra: Ghanaian-news, June 7,2020

Thielke, Tilo (2020): Gefahr auf der Straße - Südafrika will Tausende Gefangene freilassen. Capetown: Frankfurter Allgemeine Zeitung (faz), 14. May 2020

Triebe, Benjamin (2020): London spricht endlich mit Washington über Freihandel - das ist den Brexit nicht wert. Zürich: NZZ, 6 May 2020

Thum, Ulrich (2020): Corona in Nigeria: Mangelnde politische Führung und schlechte Kommunikation. Berlin: Vorwärts, 14. April 2020

Wambu, Wainaina (2020): UK seeks to build Kenya investment ties as Brexit beckons. Nairobi: Standard digital, 22 January 2020

Wane, Fatimata (2020): Brexit : quelles conséquences en Afrique ? Paris: France 24, Le Journal de l'Afrique, 31/01/2020

WHO (2020): COVID-19 - Situation update for the WHO African region - External situation report 7. Geneva: World Health Organization, 15 April 2020

World Bank (2020): World Bank Predicts Sharpest Decline of Remittances in Recent History. Washington D.C.: Press release, April 22, 2020 
Abstract : Although Britain has been so far the hardest hit among the EU member states by the Corona pandemic, Johnson persists to leave the EU at the end of 2020, whatever the cost. Presumably, the pandemic will have a by far bigger impact on the UK African trade than a no-deal Brexit. In Sub-Saharan Africa, South Africa had been arguably the hardest hit country both by Brexit and Corona. However, the poor, mainly working in the informal sector, were more concerned about the economic impact of the pandemic than the disease itself. In Nigeria, many people envisaged Corona as a plague of the rich and the elite. President Buhari shared the hubris of many British that they are less vulnerable to the pandemic and could continue with high-flying Post-Brexit plans. Ghana counts among those countries in SubSahara Africa which has been most severely hit by the Corona pandemic. But unlike South Africa and Nigeria, the direct effects of the pandemic on the downturn of its economy are not as significant as in other African states. In Kenya the number of Corona-death had been much lower than for the SARS pandemic of 2003, but the transmission of the COVID-19 virus had been significantly greater. Nevertheless, many Kenyan's saw the Brexit as a disguised blessing because they pined their hope on massive FDI by UK investors. In any case, it is clear beyond doubt that those who are to suffer most by the combined effects of the Coronapandemic and Brexit in Africa (and presumably world-wide) are the poor and vulnerable.

Zusammenfassung: Obwohl Großbritannien unter den EU-Mitgliedstaaten bislang am stärksten von der Koronapandemie betroffen war, besteht Johnson weiterhin darauf, die EU Ende $2020 \mathrm{zu}$ verlassen, unabhängig von den Kosten. Vermutlich wird die Pandemie einen weitaus größeren Einfluss auf den afrikanischen Handel im Vereinigten Königreich haben als ein No-Deal-Brexit. In Afrika südlich der Sahara war Südafrika sowohl vom Brexit als auch von Corona das vermutlich am stärksten betroffene Land. Die Armen, die hauptsächlich im informellen Sektor tätig sind, waren jedoch mehr besorgt über die wirtschaftlichen Auswirkungen der Pandemie als über die Krankheit selbst. In Nigeria stellten sich viele Menschen Corona als Plage der Reichen und der Elite vor. Präsident Buhari teilte die Hybris vieler Briten, dass sie weniger anfällig für die Pandemie sind und mit hochfliegenden Plänen nach dem Brexit fortfahren könnten. Ghana zählt zu den Ländern in Subsahara-Afrika, die ebenfalls mit am stärksten von der Koronapandemie betroffen sind. Im Gegensatz zu Südafrika und Nigeria sind die direkten Auswirkungen der Pandemie auf den wirtschaftlichen Abschwung jedoch nicht so bedeutend wie in anderen afrikanischen Staaten. In Kenia war die Zahl der Koronatoten viel geringer als bei der SARS-Pandemie von 2003, aber die Übertragung des COVID-19-Virus war signifikant höher. Dennoch sahen viele Kenianer den Brexit als verschleierten Segen an, weil sie ihre Hoffnung auf massive ausländische Direktinvestitionen britischer Investoren setzten. In jeden Fall ist klar, dass diejenigen, die am meisten unter den kombinierten Auswirkungen der Koronapandemie und des Brexit in Afrika (und vermutlich weltweit) leiden müssen, die Armen und Verletzlichen sind. 